\title{
Report
}

by the Comptroller

and Auditor General

Cabinet Office and Department for Culture, Media \& Sport

National Citizen Service 
Our vision is to help the nation spend wisely.

Our public audit perspective helps Parliament hold government to account and improve public services.

The National Audit Office scrutinises public spending for Parliament and is independent of government. The Comptroller and Auditor General (C\&AG), Sir Amyas Morse KCB, is an Officer of the House of Commons and leads the NAO, which employs some 785 people. The C\&AG certifies the accounts of all government departments and many other public sector bodies. He has statutory authority to examine and report to Parliament on whether departments and the bodies they fund have used their resources efficiently, effectively, and with economy. Our studies evaluate the value for money of public spending, nationally and locally. Our recommendations and reports on good practice help government improve public services, and our work led to audited savings of $£ 1.21$ billion in 2015 . 


\section{National Citizen Service}

Report by the Comptroller and Auditor General

Ordered by the House of Commons

to be printed on 13 January 2017

This report has been prepared under Section 6 of the

National Audit Act 1983 for presentation to the House of

Commons in accordance with Section 9 of the Act

Sir Amyas Morse KCB

Comptroller and Auditor General

National Audit Office

12 January 2017 


\section{The report examines whether the implementation of National Citizen Service has been value for money and the future risks to the programme.}

\section{(C) National Audit Office 2017}

The material featured in this document is subject to National Audit Office (NAO) copyright. The material may be copied or reproduced for non-commercial purposes only, namely reproduction for research, private study or for limited internal circulation within an organisation for the purpose of review.

Copying for non-commercial purposes is subject to the material being accompanied by a sufficient acknowledgement, reproduced accurately, and not being used in a misleading context. To reproduce NAO copyright material for any other use, you must contact copyright@nao.gsi.gov.uk. Please tell us who you are, the organisation you represent (if any) and how and why you wish to use our material. Please include your full contact details: name, address, telephone number and email.

Please note that the material featured in this document may not be reproduced for commercial gain without the NAO's express and direct permission and that the NAO reserves its right to pursue copyright infringement proceedings against individuals or companies who reproduce material for commercial gain without our permission.

Links to external websites were valid at the time of publication of this report. The National Audit Office is not responsible for the future validity of the links. 


\section{Contents}

Key facts 4
Summary 6

Part One

Development and performance 12

\section{Part Two}

Setting and meeting aims for growth 27

\section{Part Three}

Setting up National Citizen Service

to meet its aims 38

\section{Appendix One}

Our audit approach 46

\section{Appendix Two}

Our evidence base 48

\section{Appendix Three}

Comparison of selected

youth programmes 51

\section{Appendix Four}

National Citizen Service Trust performance against 2015-16

grant agreement 52
The National Audit Office study team consisted of:

Mo Ahmed, Will Carruthers-Andrews, David Molony, Emma Taylor and Emma Willson, under the direction of Joshua Reddaway.

This report can be found on the National Audit Office website at www.nao.org.uk

For further information about the National Audit Office please contact:

National Audit Office

Press Office

157-197 Buckingham Palace Road Victoria

London

SW1W 9SP

Tel: 02077987400

Enquiries: www.nao.org.uk/contact-us

Website: www.nao.org.uk

Twitter: @NAOorguk 


\section{Key facts}

\section{3,000}

estimated National

Citizen Service (NCS)

participants, 2016

\section{$23 \%$}

current annual growth rate in participants, 2015 to 2016

\section{0,000}

aim for NCS participants, 2020-21

£1.26 billion grant funding committed by government, 2016-2020

$£ 1,863 \quad$ estimated full unit cost per participant completing NCS, 2016

£10 million estimated amount paid to providers for NCS places that were not filled in 2016 and that may be reclaimed

$40 \%$ required annual growth from 2016 NCS participants to provide spaces for 360,000 in 2020

$55 \%$ percentage of young people aware of NCS, July 2016

9 months estimated lead-in time for setting up an NCS programme

32\% percentage of participants from minority ethnic groups, 2016 
Most National Citizen Service programmes comprise:

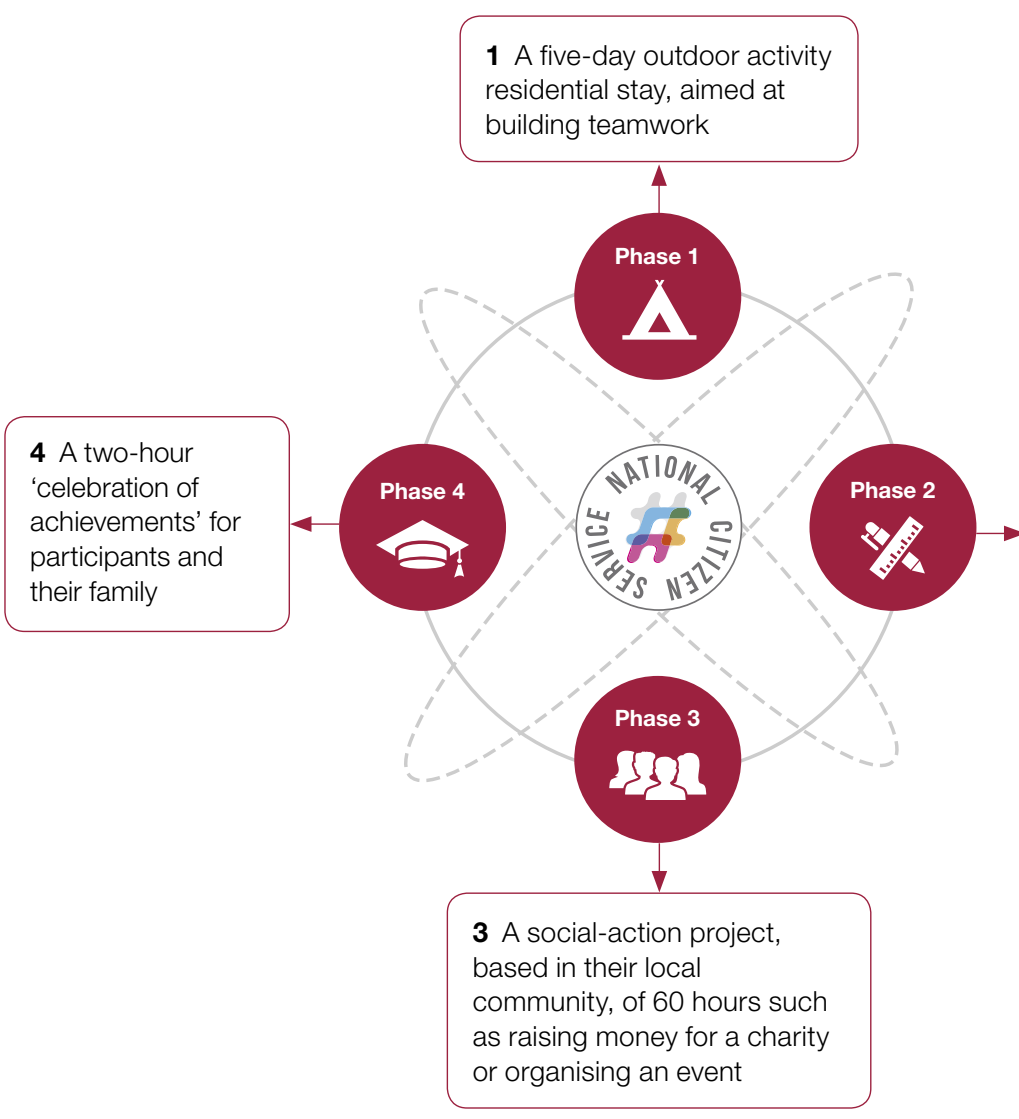

2 A five-day residential stay, often in university accommodation, to learn 'life skills', prepare for independent living and learn about the community 


\section{Summary}

1 The Cabinet Office established National Citizen Service (NCS) programme in 2011 as part of its 'Big Society' agenda to bring together local communities. This followed earlier pilots supported by the Conservative party. The then Prime Minister's stated ambition was for NCS to become universal and a 'rite of passage' for young people and lead to a more responsible, cohesive and engaged society. It aims to bring together 16- and 17-year-olds from different backgrounds to support their local community and their transition into adulthood through developing teamwork, leadership and communication skills.

2 An NCS course is normally four weeks and involves groups of 12 to 15 young people undertaking an outdoor residential to improve team-building skills; a residential to learn life skills and prepare for independent living; and a community project, such as planting a communal garden or arranging a family fun day. All 16- to 17-year-olds across England and Northern Ireland can participate.

3 In 2013 the Office for Civil Society (OCS), then part of the Cabinet Office with the responsibility for NCS, set up the NCS Trust (the Trust) as a community interest company funded by the OCS, to take over managing NCS. The Trust is responsible for increasing the number of young people participating in NCS, ensuring a high-quality NCS, reducing costs and ensuring the long-term sustainability of NCS. Since NCS launched, the OCS and, latterly, the Trust have focused on growing participation and demonstrating that NCS has an impact on young people. Up to 2015-16, the OCS spent £443 million and committed a further £1.26 billion to 2020.

4 The Trust contracts third parties to provide NCS across 18 regions, coordinating the programme itself in one area. It pays them to go into schools, sign up young people, and run courses. It currently contracts nine providers, including three private sector companies and four not-for-profit bodies. Providers work with 300 other organisations, most of whom are not-for-profit local bodies specialising in youth work.

5 In July 2016, the government announced that the Department for Culture, Media \& Sport (DCMS) would take responsibility for the OCS and NCS from the Cabinet Office. It also intends for the Trust to become a Royal Chartered body. A draft charter is currently being considered by Parliament alongside the National Citizen Service Bill, which aims to ensure NCS becomes a 'national institution', and governance and accountability match NCS funding.

\section{Scope of this report}

6 In this report we consider how well the implementation of NCS represents value for money, both now and in the longer-term. Specifically, we look at the early programme performance (Part One); the OCS's approach to setting out its aims and targets (Part Two); and how well the OCS and Trust manage the programme (Part Three).

7 Appendices One and Two provide full details of our approach and methods. 


\section{Key findings}

NCS has had early successes but it is too early to assess its long-term impact

8 Since being piloted in 2011 and 2012, NCS has grown rapidly with 93,000 young people participating in 2016. Over the past six years, 300,000 young people have participated. Around 17,000 more young people undertake NCS each year, with the number of participants increasing 31\% and 23\% in 2015 and 2016 respectively. As a result, 12\% of those eligible for NCS in 2016 had participated in the programme (paragraph 1.10 and Figure 4).

9 NCS participants come from diverse backgrounds, with a higher proportion of people from disadvantaged backgrounds than the general population.

NCS aims to encourage young people from different backgrounds to mix through a local, community-based programme. Our analysis showed that nationally a range of young people have undertaken NCS, with a greater proportion from minority groups, such as those on free school meals, than the national population. However, it also showed that the population of some local areas did not include a mix of young people with different characteristics, in particular ethnicity and income, and that at a local authority level the mix of NCS participants has not always reflected local area characteristics (paragraphs 1.11 to 1.15 and Figures 5 and 6).

10 External evaluations show NCS has an initial positive impact on participants, and participants would recommend NCS to others. Evaluations, commissioned by the OCS, show NCS has a positive effect on how a sample of young people feel and perceive themselves three to five months and 16 months after the programme. Three to five months after the programme, $80 \%$ of young people felt more positive towards those from different backgrounds and $70 \%$ were more likely to help in their local area (paragraphs 1.16 and 1.17, Figure 7).

11 As NCS pilot participants will have reached 21 years of age in 2016, it is too early to say whether the programme is going to meet its long-term objectives of contributing to a more responsible, cohesive and engaged society. Independent evaluations assess the impact of NCS on a sample of participants three to five months, sixteen months and two years after the programme. However, the OCS has not yet established a baseline to assess longer-term performance or identified how longer-term outcomes could be tracked, which can be difficult to do. It is currently considering how to make the most of its ability to match individuals' information across government datasets (paragraphs 1.18 and 1.19).

Although NCS participation has grown, this has not been as quickly as desired and the extent of potential future growth is unclear

12 Participation in NCS is not increasing as fast as the OCS or Trust hoped. In February 2016, the OCS set an aim to grow participation to 360,000 (60\% of 16-year-olds) in 2020-21, quadruple that of 2016. If the number of participants continues to increase at the current annual rate of $23 \%$, there would be 213,000 participants in 2020-21 (paragraphs 2.2 and 2.3, Figure 9). 
13 The OCS also set annual participation targets, which have not been met. Alongside longer term aims, spending review limits and requirements for multi-year provider contracts, the OCS sets annual targets to grow NCS. The Trust did not meet this target in 2016, with actual participation 13\% lower. Before 2016, the OCS did not consider prior performance or evidence of what could be achieved when setting targets. In 2015-16, the participation target exceeded the number of places providers were contracted to provide by $29 \%$. For 2016-17, the OCS set the annual target equal to the contracted number of places which had already been set when contracts agreed in 2014 (paragraphs 2.12 and 2.13, Figure 13).

14 It is not clear whether the OCS and Trust can accelerate growth of NCS participants at the pace aspired. The Trust's modelling, from summer 2015, showed NCS participation could increase to 269,000 through, for example, business as usual growth and policy changes. It is unclear how OCS used this analysis to set its 360,000 participation aim. The Trust updated its plans in response to this aim. These included young people being automatically enrolled on NCS, with an option to opt-out, supported by a formal requirement that schools promote NCS and NCS is considered in school inspections. In May 2016, the Queen's speech introduced the NCS Bill, which proposed a formal duty on schools to promote NCS. This did not reflect the Department for Education's published commitment. However, the Bill, laid before Parliament in October 2016, did not reference this duty. The OCS continues to consider next steps (paragraphs 2.5 to 2.10 and Figure 10).

15 OCS and the Trust recognise barriers to participation but, working with others, can do more to overcome these. Funding has been available for all those who want to participate in NCS, but young people do not attend for a range of reasons. NCS participants come from $88 \%$ schools targeted by the Trust, but only $63 \%$ of independent schools. The Trust's analysis shows that $55 \%$ of 17 -year-olds are aware of NCS, and that to raise participation to $360,00070 \%$ of young people would need to be aware of NCS. In 2016, $26 \%$ of young people expressing an interest in NCS went on to complete the programme. Of the 8,500 people withdrawing in summer 2016, 20\% were busy doing other things and 17\% were on holiday (paragraph 2.11 and Figures 11 and 12).

16 Ambitious aims and stretch targets have encouraged significant growth, but have come at a financial cost. The Trust has focused its efforts on meeting targets alongside considering the programme's performance. A focus on growth also encouraged the Trust to use certain media, such as television, in addition to social media. It also led the Trust to pay providers an estimated £10 million, in line with the contract, for places that were not filled which it plans to recover, for the first time, in 2016 (paragraphs 2.14 to 2.16 and Figure 14). 
The management of NCS has not kept pace with its growth

\section{Governance of NCS}

17 The Trust was set up in 2013 to manage NCS outside of government.

The OCS formed the Trust with the intention of better supporting the long-term sustainability of NCS and to allow efficient and effective programme expansion and innovation. It set the Trust up as a community interest company, rather than an executive agency, to give it more independence outside of government. The National Citizen Service Bill, currently going through Parliament alongside a draft Royal Charter, aims to ensure its governance and accountability are appropriate for the increased level of public funds it will manage (paragraph 1.5 to 1.9).

18 It has taken time for the Trust to develop some of the capability necessary to deliver a programme the scale of NCS. In its first year, the Trust set up processes to manage its contracts with NCS providers and responded to poor performance. The Trust relied on data from providers' own systems on participation and school involvement until 2015 when it set up a single data system. During 2016, the Trust has made a number of senior appointments to bring in greater management and commercial capability (paragraph 3.2).

19 Processes, across the OCS and Trust, have not suited the desired pace of growth. The autumn 2015 Spending Review set out the maximum annual NCS funding to 2019-20. The OCS believes this, alongside multi-year contracts between the providers and the Trust, provide certainty over funding. At a more detailed level, the OCS agrees the Trust's business plan and annual grant each March for the following financial year. This cycle means the OCS cannot confirm precise funding and targets, which could differ from high-level projections, with the Trust until six months into the planning cycle. At this point, the Trust and providers have already taken most of the decisions and had to invest in future programmes. It has also led to attempts to learn and plan being carried out too quickly and against conflicting priorities. The Trust has also made commercial decisions late in the process, partly because of the continual cycle of NCS programmes, distracting providers and impacting their ability to plan (paragraphs 3.3 to 3.8 and Figure 15).

\section{Commercial arrangements}

20 The OCS and then the Trust have created a market of providers and are on their second round of contracts. NCS providers covered 19 defined regions. The Trust relies heavily on the Challenge Network, which are contracted to provide $43 \%$ of places, some of which it sub-contracts, across seven regions, the maximum the Trust allows. The Challenge Network was set up in 2009 to launch the first version of the programme and helped develop the policy. More broadly, providers put their own brand alongside NCS, which has benefits but creates a risk some participants confuse the two. This, alongside decision-making and annual processes, risks impacting the sustainability of the market (paragraphs 1.8 and 3.14). 
21 Commercial terms aim to incentivise growth, but have not led providers to achieve the desired level of growth, and do not explicitly encourage them to innovate or meet all the NCS societal aims. The payment-by-results structure encourages providers to agree a high number of commissioned places and incentivises growth through bonus payments where more young people participate. However, in 2016, five of the nine providers did not meet their target for filling these commissioned places. Providers receive 5\% of the total cost for meeting objectives linked to social cohesion. Payments are not linked to other NCS aims, such as social responsibility and engagement (paragraphs 3.10 to 3.13 and Figure 16).

22 New commercial arrangements need to be in place by autumn 2018. Since autumn 2016, the Trust has been considering options to change the commercial model. With 18 months left until new contracts need to come into force it has limited time as market engagement and procurement can take more than a year to conduct for contracts of this scale (paragraph 3.14).

\section{Cost control}

23 The OCS and Trust do not yet fully know how much NCS should cost and, so far, have not prioritised cost control. The OCS funds the Trust through a grant. It has not developed a full cost model to understand what it should be paying the Trust per participant and the OCS told us it requested funding from HM Treasury based on provider costs. The Trust has cost control as one of its four strategic objectives. Our analysis of the Trust's board minutes and papers shows the Board has not focused on understanding and controlling costs. The Trust's business plan includes initiatives focusing on cost control. It is in the early stages implementing these initiatives and told us that it continues to see cost as a priority from 2017 onwards (paragraphs 3.16 to 3.17, Figures 14 and 17).

24 NCS has cost more per participant than was anticipated and needs to reduce by $29 \%$ to remain within the Spending Review limit. To date, the Trust's spending has been within the funding made available as part of the Spending Review process. Taking into account all NCS costs, OCS and the Trust currently expect to spend £1,863 for each participant in 2016. However, the autumn 2015 Spending Review implied a unit cost of $£ 1,562$ per participant in 2016, lower than the Trust's target unit cost of £1,794 agreed between the Trust and OCS in the grant agreement. The cost per participant needs to fall by $29 \%$, to $£ 1,314$ in 2019, for the Trust to provide 300,000 places and stay within the funding envelope made available as part of the autumn Spending Review. The OCS and Trust forecast unit costs will decrease over time as participation numbers increase, investment costs reduce and they reconsider how NCS will be delivered. Providers currently receive $83 \%$ of NCS spend, which is fixed in the contracts. Achieving the required cost reductions depends on commercial negotiations in 2018 and reducing the remaining $17 \%$ of costs which cover the Trust's running costs, marketing, transformation and investment costs (paragraphs 3.18 to 3.19 and Figure 17).

\section{VFM Conclusion}

25 It is still early days, but NCS has shown it can attract large numbers of participants and participation has a positive short-term effect on young people. These are no small achievements. However, it remains unclear whether these effects are enduring, whether NCS can grow to become 'a rite of passage' available to all 16- to 17-year-olds or whether NCS will realise its longer-term aims of contributing to social cohesion, responsibility and engagement. 
26 NCS is now at a critical stage. Having shown the concept of a national citizen service has something to offer young people, to demonstrate value for money the OCS and the Trust now need to show they can grow NCS as intended and run it at more affordable cost to the taxpayer. As currently constituted, it is not clear how the programme will do this. Weaknesses in governance and cost control need to be addressed. Notwithstanding the limited time available to adjust the next round of contracts, the OCS and Trust need to think carefully about their plans to take the NCS to scale.

\section{Recommendations}

27 With DCMS taking responsibility for OCS and NCS offering an opportunity to revisit aspirations for growth, NCS is at a critical point. Both OCS and the Trust need to consolidate learning, understand what is possible and begin to build a mature programme. They need to:

a identify and understand the maximum likely voluntary participation. Undertaking an evidence-based assessment to understand what can be realistically achieved, within what timescale, and at what cost, will allow OCS to set stretching but realistic ambitions.

b think innovatively about how best to achieve NCS's aims cost-effectively. Working with the market, participants and wider stakeholders, the OCS and Trust can think radically about the aspects of the current programme that work. This could include analysing the marginal benefit of each course component to understand what is critical, and can be rolled out at scale, and how other organisations could be involved in providing NCS.

c think innovatively about the best way to manage the supply chain. The Trust has started to engage the market to identify future delivery models. This should consider the full range of options for potentially delivering NCS, from contracting to setting a regulatory framework for a market of providers with greater user choice.

d work alongside government to identify what support is possible and make sure this is given. We have seen how significant NCS growth cannot be achieved without cross-government support. OCS needs to build on existing work with wider government to understand how NCS fits into the government's agenda and to identify and exploit opportunities.

e establish plans to evaluate the longer-term outcomes of NCS for young people and communities. For NCS to be sustainable and continue to attract the funding it has to date, the impact of its short- and long-term outcomes needs to be clear. An approach to assessing outcomes needs to be set up now. This could include OCS using its powers to link datasets across government.

f Allow the necessary time to develop this thinking and the future approach. Considering what can be achieved, and how, for a new and evolving programme takes time. This becomes more difficult when operations and programmes continually expand without pausing to assess progress. 


\section{Part One}

\section{Development and performance}

1.1 National Citizen Service (NCS) aims to promote a more cohesive, engaged and responsible society by providing a community-based programme for groups of young people. Since the programme was introduced in 2011, the number of young people participating has increased significantly. In this part, we review how the programme has developed and what it has achieved.

\section{The NCS vision}

1.2 In 2011 the Cabinet Office set-up the NCS programme, managed within the Office for Civil Society (OCS), as part of the government's 'Big Society' agenda to bring together local communities. ${ }^{1}$ This built on earlier work and pilots in 2009. The then Prime Minister's ambition was for NCS to become universal and a 'rite of passage' for young people. NCS aims to promote a more:

- $\quad$ cohesive society by mixing young people from different backgrounds;

- responsible society by supporting the transition into adulthood and development of employment skills such as teamwork, leadership and communication; and

- $\quad$ engaged society by enabling young people to work together to carry out projects in their local communities.

The OCS and Trust told us the long-term objectives of NCS have evolved from these, which are detailed in the business case, grant agreement and evaluation reports, to contributing to a more socially mobile, socially cohesive and socially engaged society.

1.3 All 16- and 17-year-olds across England and Northern Ireland can choose to participate in NCS. The programme involves groups of 12 to 15 young people completing a series of activities over two to four weeks (Figure 1). This includes an outdoor residential week aimed at building team work, a residential for participants to learn 'life skills' and a community-based social project ranging from building a sensory garden for a hospice to arranging a family fun day. NCS aims to encourage young people to become more socially engaged, alongside building life skills and confidence. Other international youth schemes we have seen are structured differently (Appendix Three). 


\section{Figure 1 \\ The NCS process for young people}

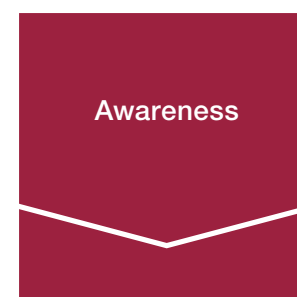

Express interest

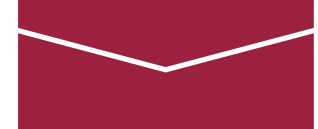

Sign-up

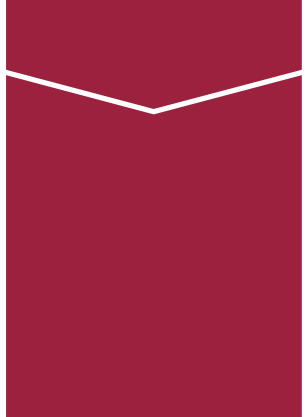

Attend

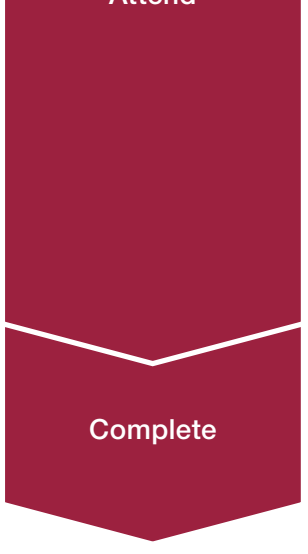

Source: National Audit Office
National and local marketing directed at young people and their parents through, for example, television and social media.

Advertising in schools through assemblies and tutor groups with the aim of organising events in $85 \%$ of mainstream schools.

Young people register their interest on the Trust's website or at school assemblies.

Regional providers follow up with young people and provide further information.

Parents or guardians pay a $£ 50$ contribution. In 2016, the average contribution was $£ 30$ due to concessions and bursaries.

Regional providers aim to allocate young people to a group within 14 days.

Parents and participants invited to induction and provided additional information.

$78 \%$ of participants undertake the four-week programme over summer. This involves 12 to 15 young people undertaking, within their groups, the following sequence of activities:

1 A five-day outdoor activity residential stay, aimed at building teamwork.

2 A five-day residential stay, often in university accommodation, to learn 'life skills', prepare

2 A five-day residential stay, often in university accomm
for independent living and learn about the community.

Phase 3

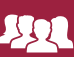

3 A social-action project, based in their local community, of 60 hours such as raising money for a charity or organising an event.

4 A two-hour 'celebration of achievements' for participants and their family.

Opportunities for young people to continue involvement.

\section{Providing NCS}

1.4 The OCS piloted NCS in selected regions over 2011 and 2012 with a total of 34,000 participants. It rolled out NCS nationally from 2013 (Figure 2 on pages 14 and 15). To provide young people a choice over when they do NCS and increase participant numbers, it added shorter autumn and spring programmes in 2012 and 2013 respectively. Around one-fifth of participants (22\% in 2016) take part in these shorter programmes. 


\section{Figure 2}

NCS timeline, 2010 to 2020

\section{Operational activity}

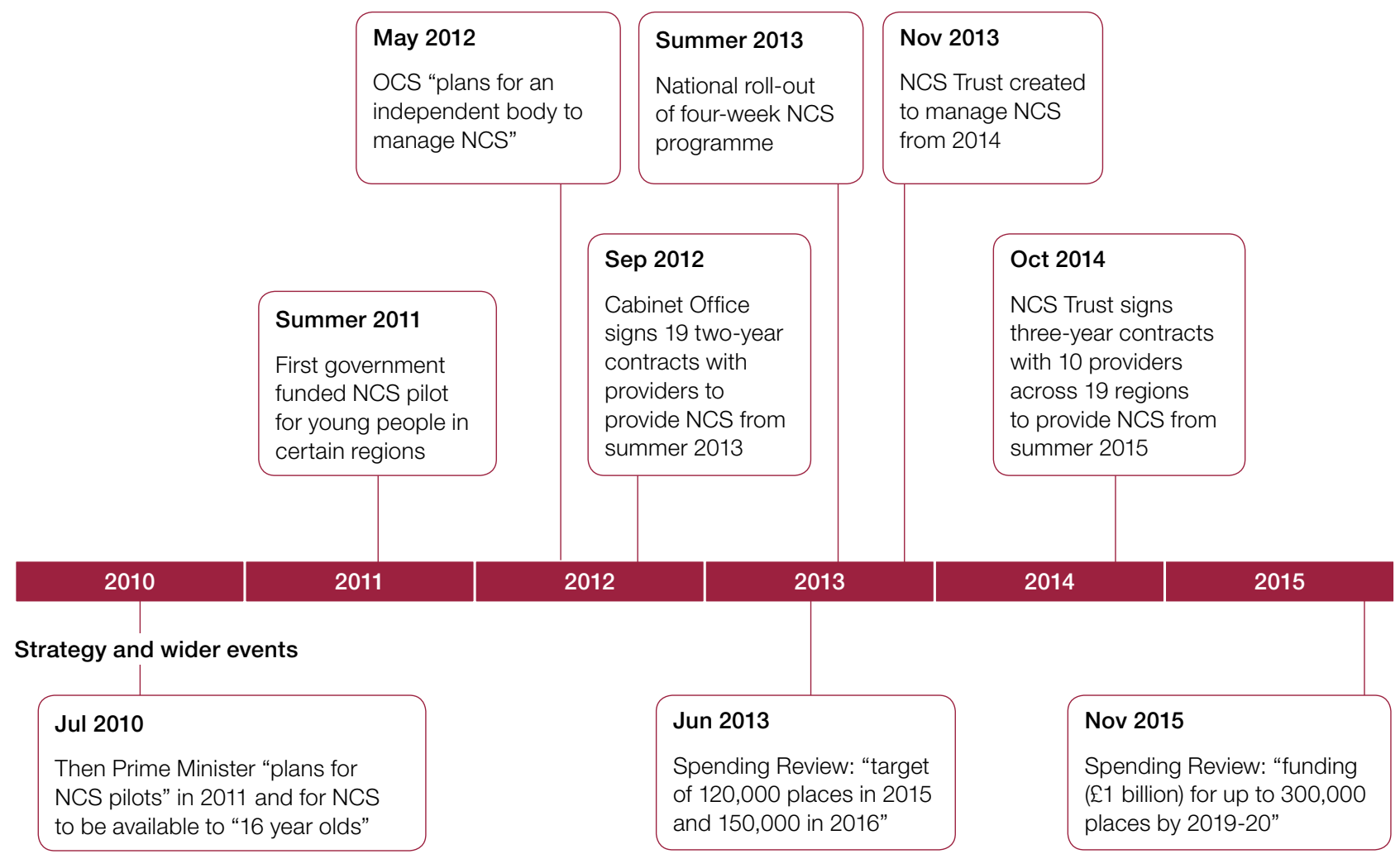

\section{Notes}

1 NCS Patrons: a cross-sector group of ambassadors, individuals successful in their field, whose role is to promote and support NCS.

2 Ongoing contracts with providers were novated from the Cabinet Office to the Trust in 2014. 


\section{Feb 2016}

NCS Trust completes

plan for 2020 ambition

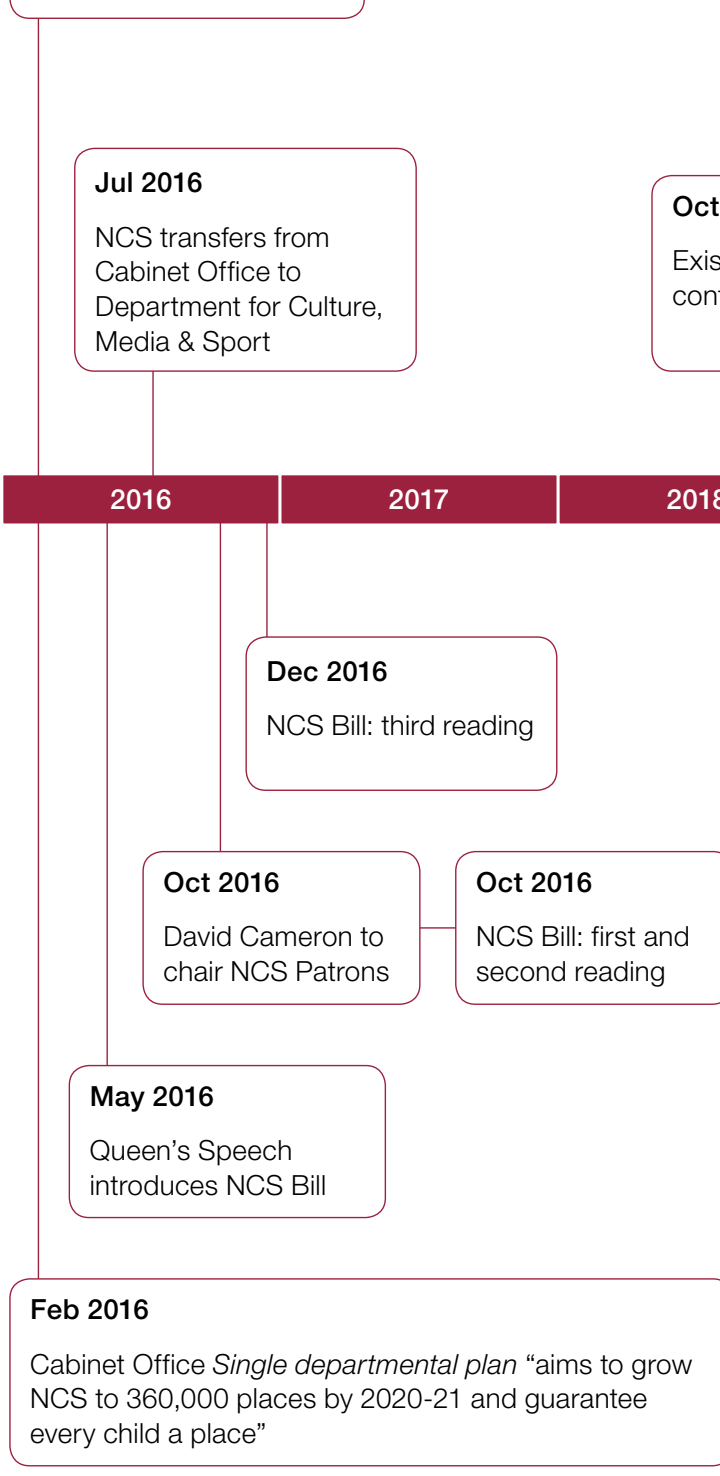


1.5 In November 2013, the OCS established the NCS Trust (the Trust), a not-for-profit community interest company, to manage the programme from 2014. The OCS believed that this would allow the Trust to operate outside government; to better support the long-term sustainability of NCS; and to encourage innovation and a more efficient and effective expansion of the programme.

1.6 The OCS set up the Trust quickly. It outlined models for providing NCS from April 2013, such as outsourcing or an independent grant-funded company. However, the OCS's business plan from May 2012 already indicated its intention to establish an independent body by March 2013.

1.7 The respective roles and responsibilities of the OCS and the Trust are outlined in the Trust's grant agreement (Figure 3). As the policy owner, sponsor and accountable body, the OCS sets the ambition and requirements for NCS. The Trust provides the programme and has responsibility for most of the controls that need to be exercised to meet the NCS ambition. As set out in the grant, its aims are to:

- increase the number of young people participating in NCS by raising awareness of the programme and encouraging young people to take part;

- ensure that high-quality NCS places are provided;

- $\quad$ secure sustainability by building a broad base of support through increasing strategic partnerships and support from senior officials and MPs; and

- improve value for money for taxpayers by reducing costs.

1.8 The Trust contracts with nine providers, across 19 regions, to provide NCS in England. ${ }^{2}$ The providers include limited companies, social enterprises and charities. One provider, the Challenge Network, provides NCS in seven regions, the maximum the Trust allows. They are contracted to provide $43 \%$ of NCS places in 2016, some of which they sub-contract to local providers. Set up in 2009, it launched a small summer programme for 158 young people that would later become NCS. The Challenge Network is now focused on NCS, with $95 \%$ of its income deriving from NCS contracts. ${ }^{3}$ Of the nine providers, only the Challenge Network provides most of the end-to-end NCS process. Other providers sub-contract, to a varying extent, to more than 300 local providers. These include national charities and local voluntary organisations.

2 Trust acts as regional provider in one region. Since autumn 2012, one provider has provided NCS in Northern Ireland. Following a pilot in autumn 2014, the Welsh Government is considering future NCS programmes. The Scottish Government does not provide NCS.

3 From the Challenge Network's accounts, year ended 31 October 2015. 


\section{Figure 3}

\section{NCS roles and responsibilities}

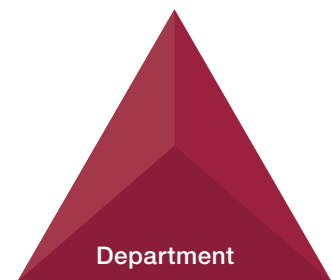

Cabinet Office to July 2016, then Department for Culture Media \& Sport

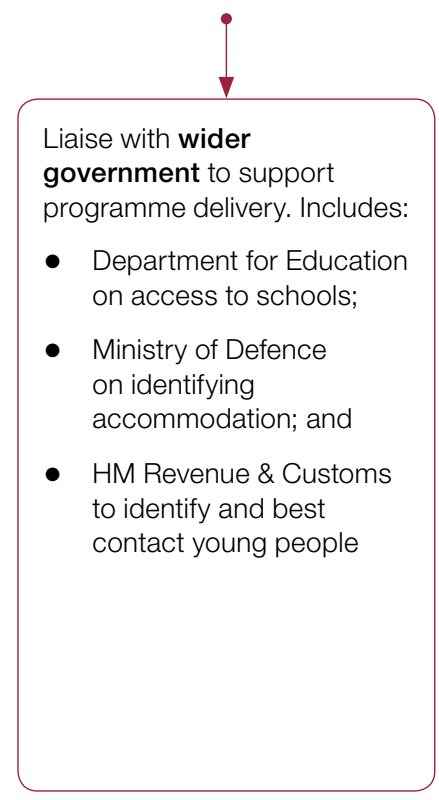

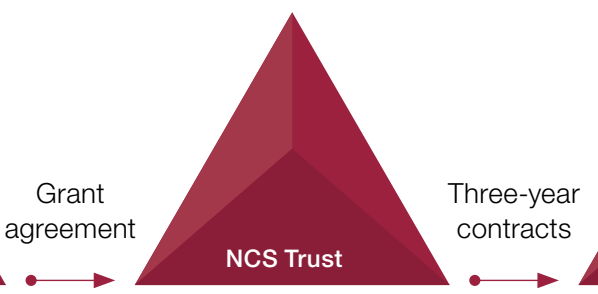

A not-for-profit community interest company
Incli

Including three charities, three social enterprises and three for-profit organisations

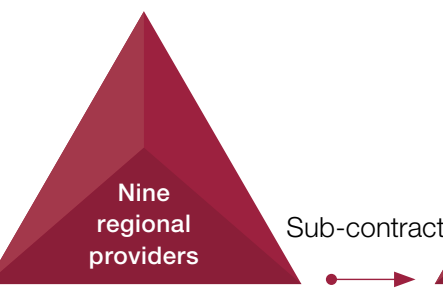

Including colleges, social enterprises and local and national charities

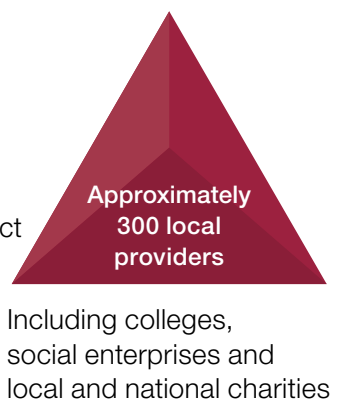

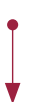

\section{Charities}

- CXK Itd (responsible for 1 region)

- EFL Trust (1 region)

- vinspired (1 region)

- The Challenge Network (7 regions)

Social enterprises

- Inspira Cumbria Ltd (1 region)

- EBP, Lincholnshire and Rutland (1 region)

Profit-making companies

- Ingeus UK Ltd (3 regions)

- Reed in Partnership Ltd (2 regions)

- Advanced Personnel Management Group (UK) Ltd (1 region)

\section{Organisation}

Department (Office for Civil Society)

NCS Trust

Regional providers

Local providers

\section{Responsibilities include:}

setting NCS policy, outlining accountabilities and aspirations, managing funding, encouraging cross-government support;

identifying and sharing best practice, national branding, marketing and communications, contracting prime providers, developing partnerships and setting programme requirements;

managing NCS (including signing up young people); identifying staff, accommodation and transport, and providing support during programmes. Sub-contract to varying degrees; and

providing NCS locally. Often the main contact for young people and their guardians.

\section{Note}

1 Regional providers: NCS Trust now coordinates NCS in one of the 19 regions. The Challenge Network provides $43 \%$ of contracted places in 2016 across seven regions; Ingeus 15\% across three regions; Reed in Partnership 10\% across two regions; all other providers each provide one region. Does not include Northern Ireland. 
1.9 The May 2016 Queen's Speech introduced plans to put the Trust on a statutory basis, increase its accountability to Parliament, and place a formal duty on schools and local authorities to promote NCS. In October 2016, a charter was laid before Parliament to establish the Trust as a Royal Chartered body. Alongside the charter the National Citizen Service Bill, which will place requirements on the new body to make it more accountable for the funding received, had its first reading in Parliament. The Bill does not include a formal duty on schools and local authorities. After its third and final House of Lords reading in December 2016, the Bill has been presented to the House of Commons. In July 2016, the new Prime Minister announced that the OCS, who has responsibility for NCS, would transfer from the Cabinet Office to the Department for Culture, Media \& Sport (DCMS). The OCS had been responsible for youth policy since 2013.

\section{Participation in NCS}

1.10 Since 2011, 300,000 young people have participated NCS, with 93,000 young people attending in 2016 (Figure 4), meaning 12\% of all those aged 16- to 17-year-olds in 2016 had participated in NCS. In 2016, participation varied across local authorities, with the proportion of 16 - to 17-year-olds taking part ranging from $4 \%$ in Torbay to $24 \%$ in Southend-on-Sea.

\section{Participants' characteristics}

1.11 A range of young people from different socio-economic backgrounds have participated in NCS, with 13\% of participants coming from the most deprived 10\% of areas in 2016 (Figure 5 on page 20). In summer 2016, 91\% of 61,875 participants for whom school data were available were from mainstream schools and $4 \%$ from independent schools. The Trust told us that, although not an official aim of the programme, it aimed for an over-representation of minority groups so NCS would help encourage social mobility.

1.12 Alongside a responsible society, NCS aims to promote a more cohesive society by mixing young people from different backgrounds, and an engaged society with young people carrying out local projects. To meet these aims, each NCS group needs to include local young people from different backgrounds.

1.13 In its annual grant, the OCS sets the Trust targets for the characteristics of those participating in NCS aligning to the local authority population (Appendix Four). For 2015-16, the Trust met two of the three targets but fell just short on its target for ethnic diversity - 88\% compared with an 89\% target - as ethnic minorities were over-represented among NCS participants. Providers receive 5\% of the contract costs if they meet social mix targets. The Trust told us that providers achieved these targets in 135 of 152 local authorities after the summer 2016 programme. 


\section{Figure 4 \\ NCS participant numbers and percentage of young people having participated, 2011 to 2016}

\section{Since $2011,300,000$ young people have completed NCS}

\section{Participant numbers (000)}

350

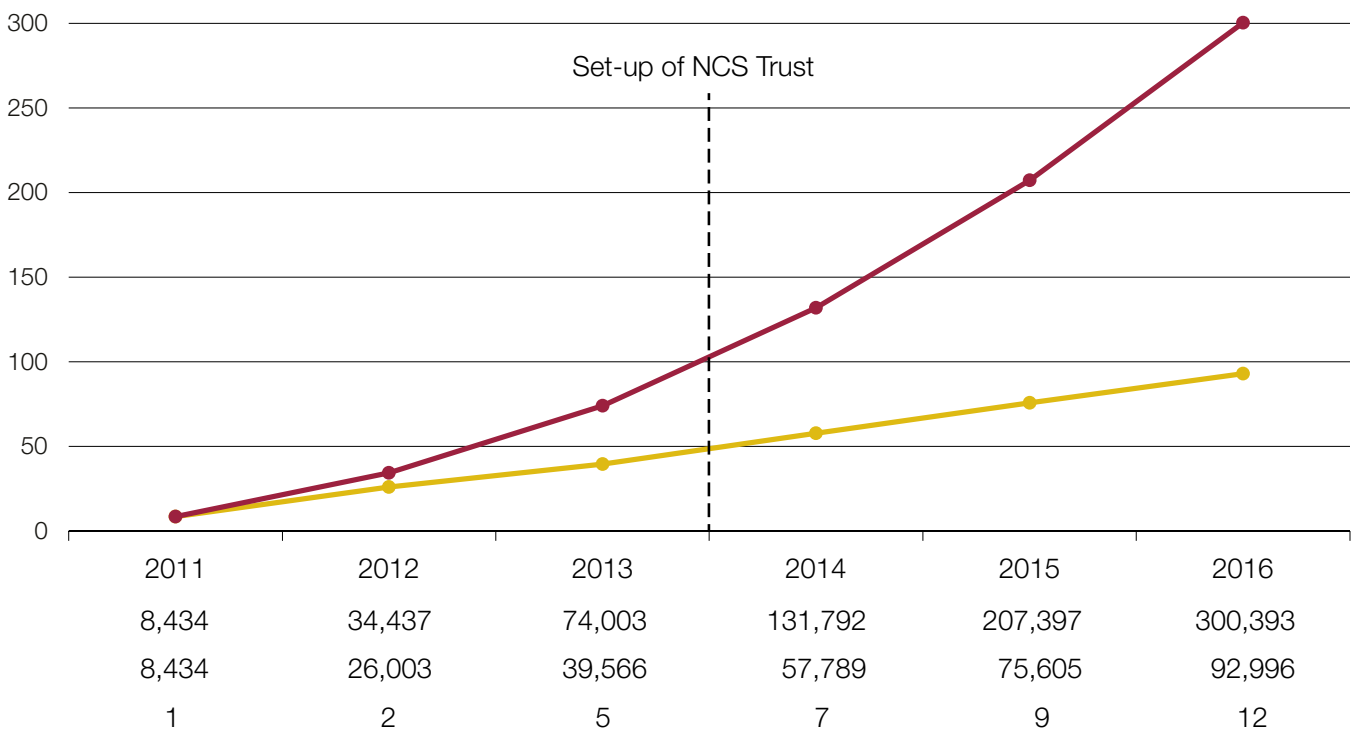

Cumulative participants

Annual participants

Percentage of 16 - to 17 -yearolds having participated (\%)

\section{Notes}

1 Participants defined as number of young people turning up for NCS for programmes ran in summer 2011; summer and autumn 2012, 2013; and spring, summer and autumn since 2014.

2 Percentage of 16- to 17-year-olds shows the number of young people having participated in NCS that year and those 17-year-olds having participated in NCS as 16-year-olds in the previous year. As data is not available showing the split of participants by age for 2011 and 2012 , we assume a similar percentage of 16-year-olds undertook the programme as in 2013.

3 Data does not include Northern Ireland.

Source: NatCen Social Research and Ipsos MORI evaluation reports; National Citizen Service Trust 2015-16 end of year report; Office for National Statistics, mid-year population estimates, 2011 to 2015 


\section{Figure 5}

\section{Characteristics of 16- to 17-year-olds participating in NCS compared with national proportion, 2016}

\section{Minority groups are over-represented among NCS participants}

Percentage of young people

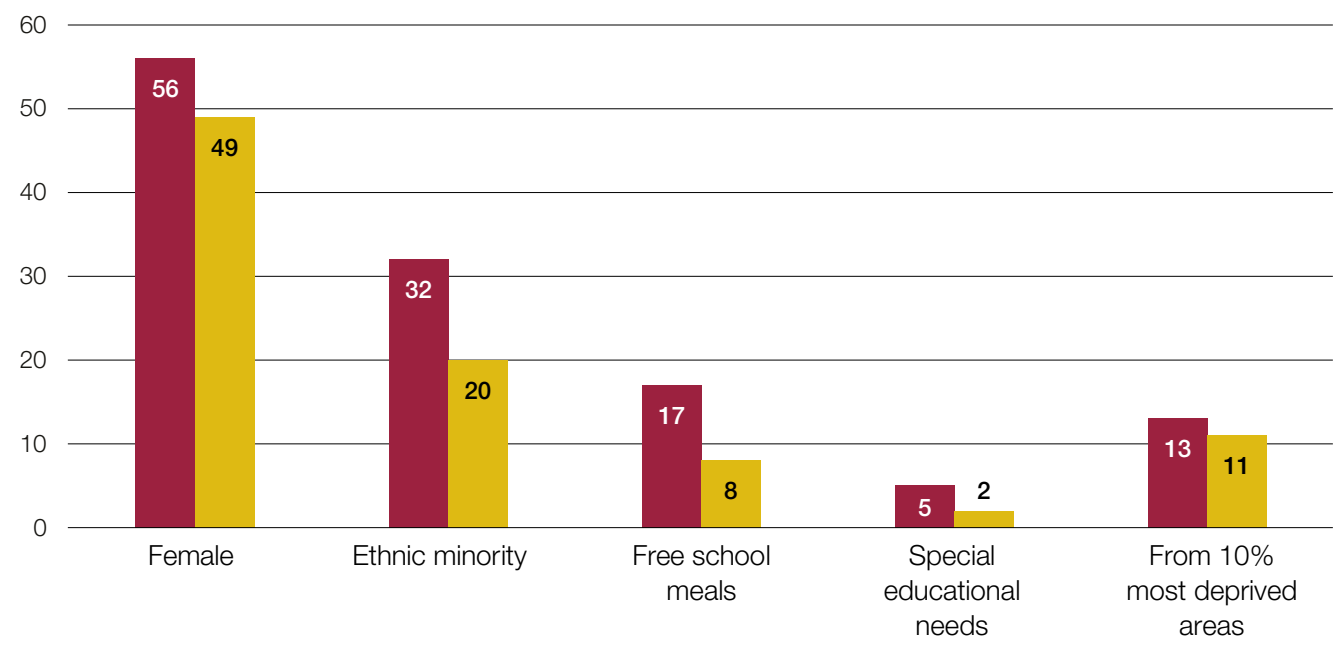

Percentage of NCS participants

Percentage of 16- to 17-year-old population in England

\section{Notes}

1 Includes information provided by 91,730 NCS participants turning up for NCS in 2016, where this information has been provided.

2 Free school meals measured against Department for Education secondary school statistics, January 2016. Based on 76,419 participants providing data. This does not include independent schools or sixth form colleges.

3 Special educational needs measured against children with statements in secondary schools, January 2015. Based on 72,196 participants providing special educational needs data.

4 Ethnicity and gender measured against local authority population statistics for 10- to 14-year-olds at time of the 2011 census. Based on 75,290 participants providing ethnicity data and 91,321 providing gender data.

5 Deprivation measured against English indices of deprivation for lower level super, output areas. Based on 82,074 participants providing postcode data that could be matched to local authorities. 
1.14 Our more detailed analysis of Trust data shows that in many local areas a disproportionate number of young people from certain backgrounds participate (Figure 6 on pages 22 and 23). This could create challenges in ensuring an appropriate mix of local young people take part, in line with NCS aims, but it may also encourage greater social mobility. Differences could be because different providers focus on certain groups, or participants recommend their friends who are often from a similar background. For instance, our analysis showed that for two regions supplied by the same provider in 2016, NCS participants were more likely to receive free school meals compared with local 16- and 17-year-olds. In Suffolk (East), 22\% of participants received free school meals compared with $11 \%$ of the local population. ${ }^{4}$ In Gloucestershire (South West), $17 \%$ of participants received free school meals compared with $8 \%$ of the local population.

1.15 Ensuring young people mix with those from different backgrounds, in particular with those from different ethnic and economic backgrounds, may be difficult to achieve without changing the local community focus of NCS. Our analysis shows that in $63 \%$ of 150 local authorities the extent to which young people could mix locally with those from different backgrounds was limited as more than $80 \%$ of young people in the local population were reported from a white ethnic background. For example, in Norfolk, a more rural community, $95 \%$ of young people from the local population class themselves as white and $88 \%$ of young people do not receive free school meals.

\section{Participants' experiences}

1.16 Young people participating in NCS have been positive about the experience. After the 2015 programme, $84 \%$ of those participating said they would definitely recommend NCS to others. Nine in ten said they found the experience worthwhile. From summer 2016, the Trust began gathering real-time feedback from participants. Feedback on social media shows examples of the positive impact NCS can have on young people:

- "I did mine [NCS] last year and it was honestly the best weeks of my life! Because of NCS I now have an internship..."

- $\quad$ "Such a brilliant scheme, it was fantastic for my daughter. She had a few personal confidence problems as a teenager, it really helped regain her confidence." 
$\frac{\check{0}}{\frac{0}{0}}$

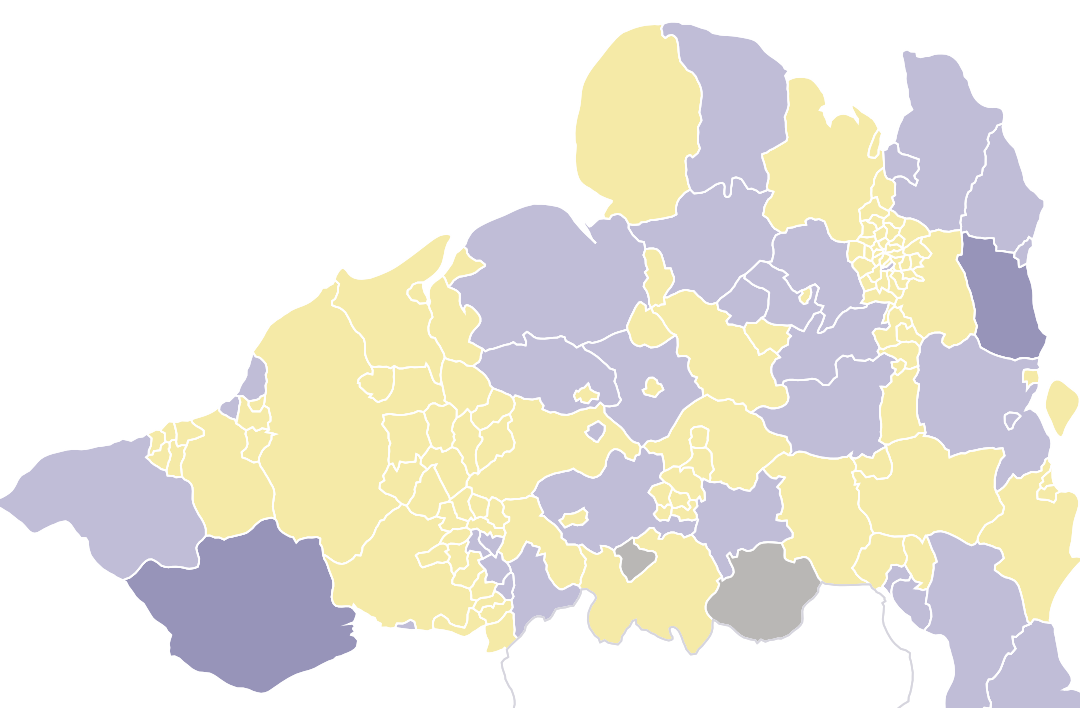

흐

$\frac{0}{.0}$

过

$\frac{\sqrt{2}}{\sqrt[\pi]{0}}$

○ 0

خ

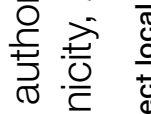

제에

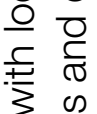

రृ $\frac{\omega}{\mathbb{1}}$

흐 ह

है $\frac{8}{0}$

क

苋

응

बิ

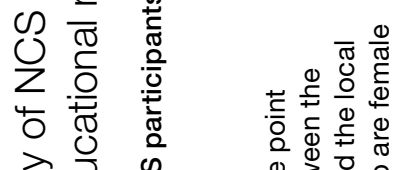

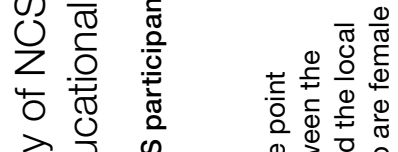

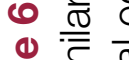

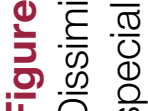

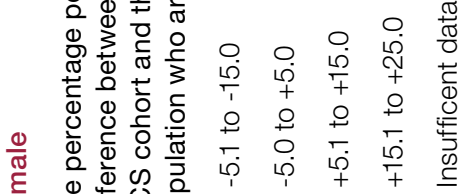

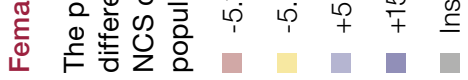




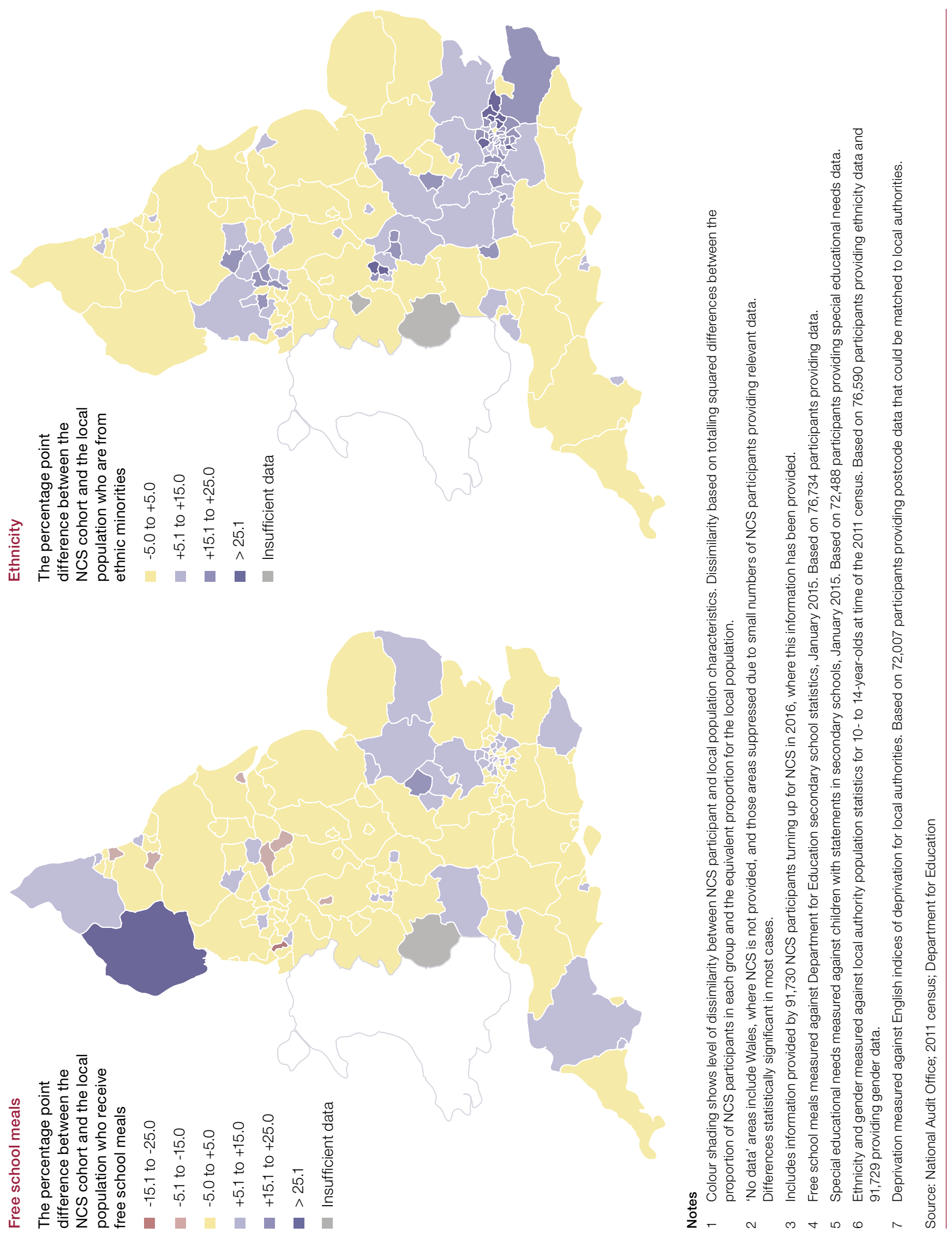


1.17 External evaluations, commissioned by the OCS, show NCS has a positive impact on the perceptions of participants (Figure 7). Evaluations assess the short-term impact of NCS on a sample of participants three to five months after completing the programme and then 16 months on. ${ }^{5}$ Shortly after the summer programme, more than $80 \%$ of young people felt more positive towards those from different backgrounds and around $70 \%$ were more likely to help in their local area. ${ }^{6}$ However, 16 months on, this fell to $57 \%$ and $38 \%$ respectively. Based on costs included in the evaluation, this led to an estimated return on investment of £2.08 for every £1 spent, for the summer 2014 programme. ${ }^{7}$

\section{Figure 7}

Summary of external evaluations of summer programmes, 2011 to 2015 NCS has had positive impacts on participants

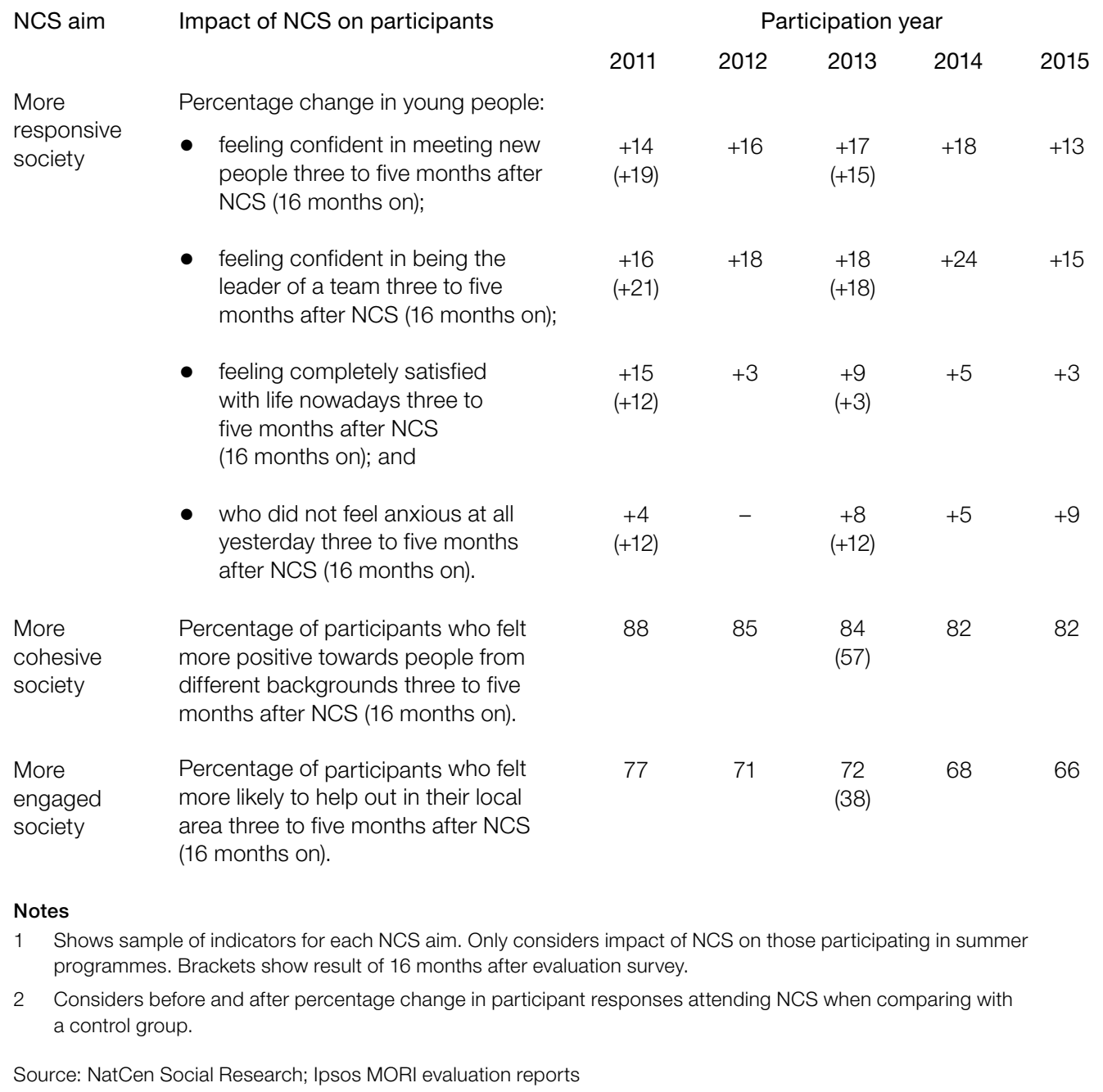

5 Sixteen months on evaluations were conducted for 2011 and 2013. A two-year evaluation has been completed for 2013, although it has not been published.

6 Represents weighted average for each year based on the number of participants on each programme across spring, summer and autumn.

7 Represents the central estimate from an estimated return on investment range. 


\section{Longer-term outcomes}

1.18 The OCS set up NCS without considering different ways it could meet its long-term aims of social responsibility, cohesion and engagement cost-effectively. The earliest business case available (November 2012) did not assess different ways of meeting the NCS aims and the OCS could not show that it had considered options before introducing NCS in 2011. The 2011 and 2012 pilots assessed how NCS was provided. Since 2013, the OCS has not undertaken a structured analysis to understand how NCS outcomes could be better met. In 2016, OCS and the Trust commissioned an external review of how NCS activities supported individual outcomes.

1.19 As those young people having participated in NCS pilots in 2011 will just be reaching 21 years of age, it is too early to say whether NCS is meeting its long-term aims of contributing to a more responsible, cohesive and engaged society. The OCS monitors the impact of NCS on a sample of participants three to five months, sixteen months and two years after the programme. However, it is yet to set up systematic processes to track and assess the lasting impact of NCS on both young people and society, and so cannot assess the extent to which NCS adds value compared with other programmes. It is currently considering how to identify and assess these longer-term outcomes, including the extent to which it can use data-matching across government datasets to identify, for example, employment outcomes. Identifying these long-term outcomes will be difficult as we have found elsewhere across government. ${ }^{8}$

\section{Costs of NCS}

1.20 In 2016-17, NCS is expected to cost a total £187 million. This includes an estimated £0.5 million for OCS oversight and an annual grant (Figure 8 overleaf) distributed to the Trust to cover:

- programme costs such as local marketing, residential accommodation and activities and programme staff costs;

- $\quad$ operating costs to run the Trust, including staff and central marketing; and

- investment costs to undertake strategic planning and build infrastructure.

1.21 Up to 2019-20, grant funding is expected to more than double to £424 million in line with the higher number of participants. HM Treasury has not yet confirmed funding to support the 360,000 NCS participation limit for 2020-21.

1.22 OCS funding covers the majority of NCS costs. The balance comes from parent or guardian contributions ( $£ 4$ million in 2016-17) and corporate contributions ( $₹ 7$ million in 2016-17) which consist of discounts, sponsorship and benefits-in-kind such as T-shirts with the NCS logo. 
Figure 8

NCS income and spend, 2014-15 to 2019-20

Up to 2019-20 grant funding is expected to more than double to £424 million

\begin{tabular}{|c|c|c|c|c|c|c|c|}
\hline \multirow{2}{*}{\multicolumn{2}{|c|}{$\begin{array}{l}\text { NCS spending } \\
\text { review settlement }\end{array}$}} & \multirow{3}{*}{$\begin{array}{c}\text { 2014-15 } \\
\text { (actual) } \\
(£ \mathrm{~m}) \\
\\
\\
-\end{array}$} & \multirow{3}{*}{$\begin{array}{c}2015-16 \\
\text { (actual) } \\
(£ m) \\
\\
164\end{array}$} & \multirow{3}{*}{$\begin{array}{c}2016-17 \\
\text { (forecast) } \\
(£ \mathrm{~m}) \\
\\
217\end{array}$} & \multirow{3}{*}{$\begin{array}{c}2017-18 \\
\text { (plan) } \\
(£ \mathrm{~m}) \\
\\
273\end{array}$} & \multirow{3}{*}{$\begin{array}{c}\text { 2018-19 } \\
\text { (plan) } \\
(£ m) \\
\\
351\end{array}$} & \multirow{3}{*}{$\begin{array}{c}2019-20 \\
\text { (plan) } \\
(£ m) \\
\\
424\end{array}$} \\
\hline & & & & & & & \\
\hline & & & & & & & \\
\hline \multicolumn{8}{|c|}{ Trust income } \\
\hline \multicolumn{2}{|c|}{ Grant funding } & 117 & 155 & 203 & 273 & 351 & 424 \\
\hline \multicolumn{2}{|c|}{ Parental contributions } & - & 1 & 4 & 5 & 5 & 8 \\
\hline \multicolumn{2}{|c|}{ Other } & 0 & 0 & 0 & 0 & 0 & 0 \\
\hline \multicolumn{2}{|c|}{ Total income } & 117 & 156 & 207 & 278 & 356 & 432 \\
\hline \multicolumn{2}{|c|}{ Non-cash contributions } & 0 & 4 & 7 & 10 & 10 & 10 \\
\hline \multicolumn{8}{|c|}{ Spend } \\
\hline \multicolumn{8}{|c|}{ Trust } \\
\hline \multicolumn{2}{|c|}{ Contract costs } & 103 & 139 & 155 & 183 & 241 & 288 \\
\hline \multicolumn{2}{|c|}{ Operating costs } & 14 & 17 & 18 & 36 & 40 & 34 \\
\hline \multicolumn{2}{|c|}{ Investment costs } & - & - & 13 & - & - & - \\
\hline \multicolumn{2}{|c|}{ Sub-total } & 117 & 156 & 187 & 218 & 281 & 321 \\
\hline \multicolumn{2}{|c|}{ OCS } & 0.5 & 0.5 & 0.5 & 0.5 & 0.5 & 0.5 \\
\hline \multicolumn{2}{|c|}{ Total spend } & 118 & 157 & 187 & 219 & 282 & 322 \\
\hline \multicolumn{8}{|c|}{ Notes } \\
\hline & \multicolumn{7}{|c|}{$\begin{array}{l}\text { The OCS spent £168 million running NCS between 2011-12 and 2013-14. The Trust, created in } \\
\text { November 2013, managed NCS from } 2014 .\end{array}$} \\
\hline \multicolumn{8}{|c|}{$\begin{array}{l}2 \text { Figures may not sum due to rounding. For each year, the Trust did not draw down all available funds, explaining } \\
\text { differences between income and spend. }\end{array}$} \\
\hline \multicolumn{8}{|c|}{3 2016-17 figures: Based on Trust forecast as at 31 December 2016 as reported to the OCS. } \\
\hline 4 & \multicolumn{7}{|c|}{$\begin{array}{l}\text { Grant funding: Shown on accruals based as per the Trust accounts. This does not reconcile to OCS accounts where } \\
\text { grants are shown on a cash basis. Other income includes £0.4 million central procurement spend. }\end{array}$} \\
\hline 5 & \multicolumn{7}{|c|}{$\begin{array}{l}\text { Parental contributions: Parents/guardians pay } £ 50 \text { per participant, except where decreased or waived given financial } \\
\text { circumstances. Before autumn 2015, providers retained contributions after which they were payable to the Trust. }\end{array}$} \\
\hline 6 & \multicolumn{7}{|c|}{ Non-cash contributions: Includes corporate sponsorships, discounts and benefits-in-kind. } \\
\hline 7 & \multicolumn{7}{|c|}{$\begin{array}{l}\text { Forecast Trust spend: Figures beyond } 2016-17 \text { based on the Trust's latest participation forecast of } 151,000 \text { in } 2018 \text {; } \\
199,000 \text { in 2019; and } 247,000 \text { in 2020. In 2016-17, operating and investment costs have only been split out. As this } \\
\text { approach is under review, these costs have been combined for future years. }\end{array}$} \\
\hline 8 & \multicolumn{7}{|c|}{$\begin{array}{l}\text { OCS spend: For } 2016-17 \text {, the OCS estimated its oversight cost } £ 0.5 \text { million. As it was not able to provide equivalent } \\
\text { figures for other years, we use } £ 0.5 \text { million as a proxy. }\end{array}$} \\
\hline
\end{tabular}




\section{Part Two}

\section{Setting and meeting aims for growth}

2.1 For the government to achieve its aspiration for National Citizen Service (NCS) to become a 'rite of passage' available to all 16- to 17-year-olds and enhance societal cohesion, responsibility and engagement, large numbers of young people need to complete NCS. This part sets out the scale of the government's ambition and the impact of ambitious growth on the programme.

\section{Scale of ambition}

2.2 From 2010, the Coalition government committed to give an NCS space to every young person who wanted one. In June 2013 it announced funding for up to 120,000 places in 2015 and 76,000 young people participated (63\% of places for which funding had been made available). As part of its autumn 2015 Spending Review, HM Treasury confirmed funding for up to 124,000 NCS places in 2016 and 93,000 young people participated filling $75 \%$ of places for which funding had been made available. It also announced funding for up to 300,000 young people to participate in 2019-20. In February 2016, the Cabinet Office outlined its aim to increase this to 360,000 places in 2020-21, four times as many places as in 2016. The NCS Trust (the Trust) then developed plans to provide 360,000 places and reach its overall aim of one million participants between 2011 and 2020.

2.3 As recognised by the OCS, Trust and providers, the desired growth in participation presents a significant challenge (Figure 9 overleaf). Achieving 360,000 participants in 2020 represents an average $40 \%$ annual growth over four years from 2016, exceeding the 2015 and 2016 growth of $31 \%$ and $23 \%$ respectively. If a 23\% annual growth rate continues an estimated 213,000 young people will take part in NCS in 2020-21. The Trust's business plan showed that achieving 360,000 participants in 2020 would require significant and critical policy changes. 


\section{Figure 9}

Spending review and actual growth in NCS participants, 2011 to 2020

Reaching 360,000 participants in 2020 requires significant growth

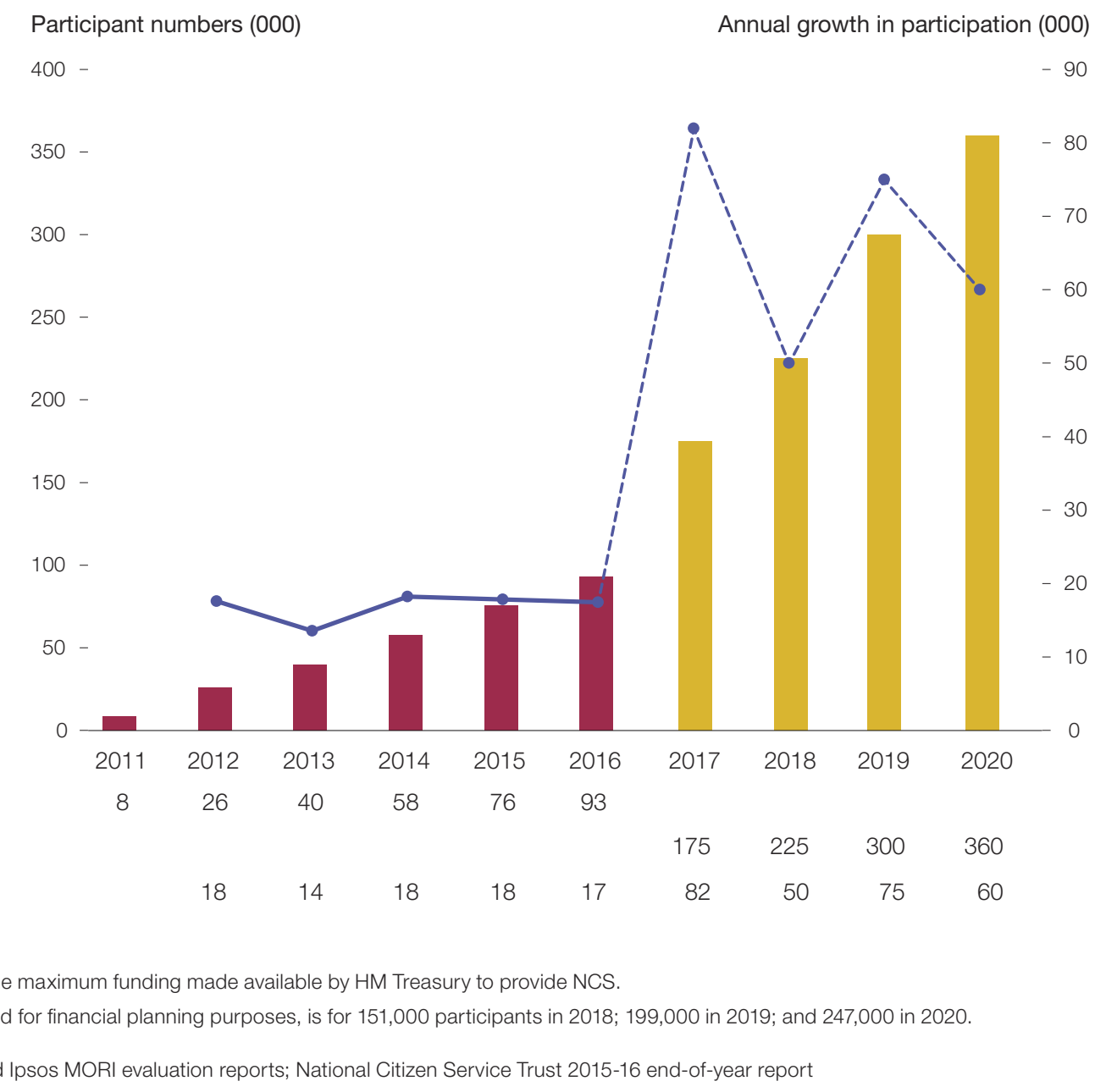

Annual participants (000)

Spending Review limit (000)

Absolute growth (000) 


\section{Setting the aims}

2.4 Setting out ambitious aims for growth can work well. The OCS, Trust and providers agree that the level of ambition has been critical in achieving growth to date. However, stretch aims and targets can also come at a cost both in terms of public confidence and inefficiencies. In 2013 and 2015, as part of the Spending Review process, the OCS agreed with HM Treasury the maximum funding available for an agreed number of NCS participants. Each year, it then sets the Trust annual participation targets as part of its grant agreement.

\section{Identifying what can be achieved}

2.5 The OCS set longer-term aims without considering what was achievable in practice, or reflecting the uncertainty of forecasting assumptions underlying its plans. In setting its aim for 360,000 young people undertaking NCS in 2020-21, the OCS did not:

- $\quad$ reflect the uncertainties associated with setting longer-term aims for voluntary programmes such as NCS, which depend on behaviours and potential policy changes;

- carry out modelling to test the criticality and sensitivity of underlying assumptions and understand the realism of ambitions set - modelling can be used to understand how participation numbers can increase based on past performance and existing or new processes or policy; and

- fully build on the Trust's operational understanding of NCS or agree its plans. From September 2015, the OCS shared with the Trust progress with Spending Review discussions. Whilst the executive team were involved in discussions, which it shared with the Trust's board, the board did not consider volumes, feed into the process or have clarity on figures until they were published in the autumn 2015 Spending Review. In summer 2015, the Trust commissioned an independent analysis of the barriers to expanding NCS. This showed a potential 269,000 participants could be expected by 2020 through business as usual growth, central investment, performance improvements and policy changes (Figure 10 overleaf). This analysis does not reconcile to the OCS's aim for 360,000 participants. The Trust shared an overview of its analysis with the OCS. 


\section{Figure 10}

Stages in developing NCS aims for growth, from summer 2015

The Cabinet Office and Trust based aims on significant policy changes which will not now happen

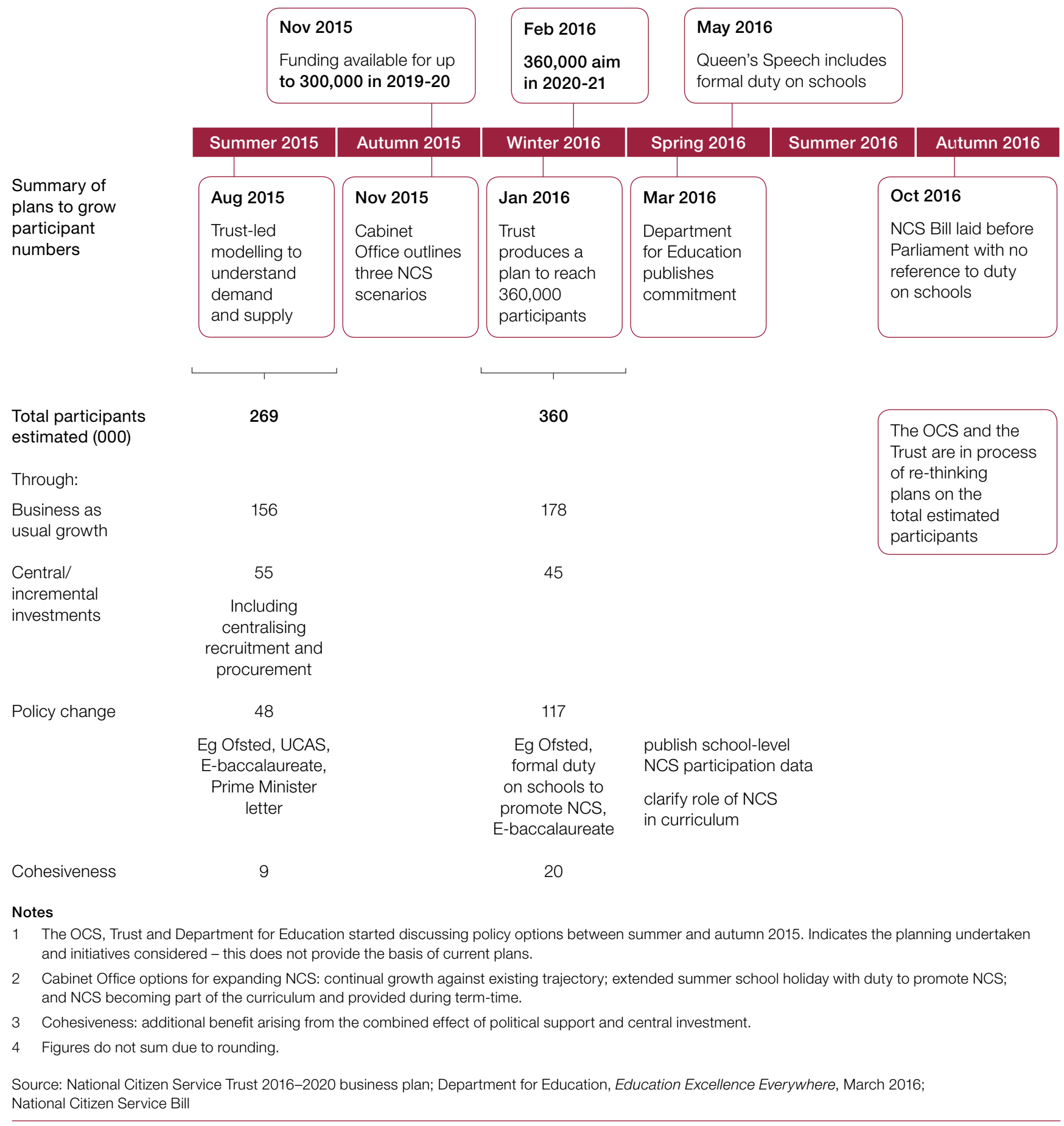


2.6 From autumn 2015, the OCS, Trust and the Department for Education began to discuss potential policy options to support the desired growth in NCS participants. Options included adapting the curriculum, publishing data on participation across schools and placing a duty on schools to promote NCS. At this stage, it was difficult to reliably assess the potential impact of these initiatives. In January 2016, the Trust shared with the OCS its five-year business plan to achieve growth to the 360,000 participants set in the OCS's plans. This included making it the 'norm' for young people to undertake NCS, with an option to opt-out. This would be supported by placing a statutory duty on schools and local authorities to promote NCS and considering NCS in Ofsted inspections.

2.7 The measures set out in the Trust's business plan have not been implemented by the OCS or the Department for Education. In March 2016, the Department for Education outlined its commitment to clarify the role of NCS within the national curriculum and publish school-level participation data. ${ }^{9}$ There were inconsistencies between the policy changes included in the Trust's plans and the Queen's speech, and the earlier Department for Education's published commitment. The Department for Education's commitments do not include placing a formal duty on schools or considering NCS in Ofsted inspections.

2.8 The OCS recognised some critical issues with the Trust's business plan, but these have not yet been fully addressed. In February 2016, the OCS reviewed the Trust's plans, seeking input from programme and commercial experts. It set out critical issues for the Trust to address, such as ensuring it had appropriate governance and contingency plans should policy changes not be implemented, without which it would not be possible to reach the Cabinet Office's participation aim. The Trust committed to address these issues through 2016-17.

2.9 In May 2016, the Government introduced through the Queen's Speech the NCS Bill. This included putting NCS on a statutory basis and placing a formal duty on schools and local authorities. In October 2016, the NCS Bill had its first reading in Parliament. It did not include a formal duty on schools or local authorities. It did reference the use of HM Revenue \& Customs data to help disseminate NCS information to young people and guardians.

2.10 Without these policy changes, alongside operational improvements, it is unlikely the OCS will meet its aim for 360,000 young people undertaking NCS in 2020. The OCS and the Trust are now re-thinking their long-term aspirations and updating their implementation plans, which took more than six months and significant amounts of time and resource to develop. 


\section{Addressing barriers to participation}

2.11 The OCS has not identified the maximum likely voluntary participation in NCS. With responsibility for providing NCS, the Trust is able to have a better understanding of what is achievable. It is currently improving its knowledge by collecting and analysing more data, identifying best practice and piloting new approaches to encourage sign-up beyond mainstream schools. However, although it recognises barriers to performance it has not yet fully considered performance to date to understand what optimum performance looks like and the extent to which barriers to performance can be overcome. This includes:

\section{- Brand awareness and recognition}

In July 2016, the Trust found that 55\% of a sample of young people were aware of NCS and that $25 \%$ were not interested in taking part. Its analysis shows that it needs to increase awareness of NCS to more than $70 \%$ to achieve the desired growth but has not considered what is possible. By way of comparison, the Trust found $78 \%$ of young people are aware of the Duke of Edinburgh scheme, which was established in 1956.

\section{- Access to schools}

Most young people come into contact with NCS at school. In 2016, the Trust or providers held events in $83 \%$ of the 4,233 schools targeted. During summer 2016, NCS participants came from 3,712 (88\%) of these schools, with a lower proportion of independent schools having NCS participants (Figure 11). The Trust found wide variations across providers in the quality of school assemblies. It is continuing work to improve interaction with schools through introducing policy initiatives developed by the OCS, training providers and developing its own capability.

\section{- Increasing the proportion of those who turn up after signing up}

Not all young people expressing an interest in NCS go on to participate. In summer 2016, 72,919 (28\%) of the 259,000 16- to 17-year-olds expressing an interest took part (Figure 12 on page 34). Young people may not sign up as they do not want to commit to the programme over their school holidays. Of the 8,500 young people withdrawing in summer 2016 for which data was available, 32\% withdrew as they no longer wanted to do NCS; $20 \%$ as they were busy doing other things and $17 \%$ as they were on holiday. After signing up, young people may lose interest if it takes too long to allocate them to an NCS programme. To achieve 360,000 participants by 2020 , the Trust estimates that $85 \%(560,000)$ of 16 -year-olds need to sign up under the current model of young people opting in to NCS. It forecast that introducing a formal duty on schools could increase participation by 117,000. 
Figure 11

Number of schools with young people participating in NCS, summer 2016

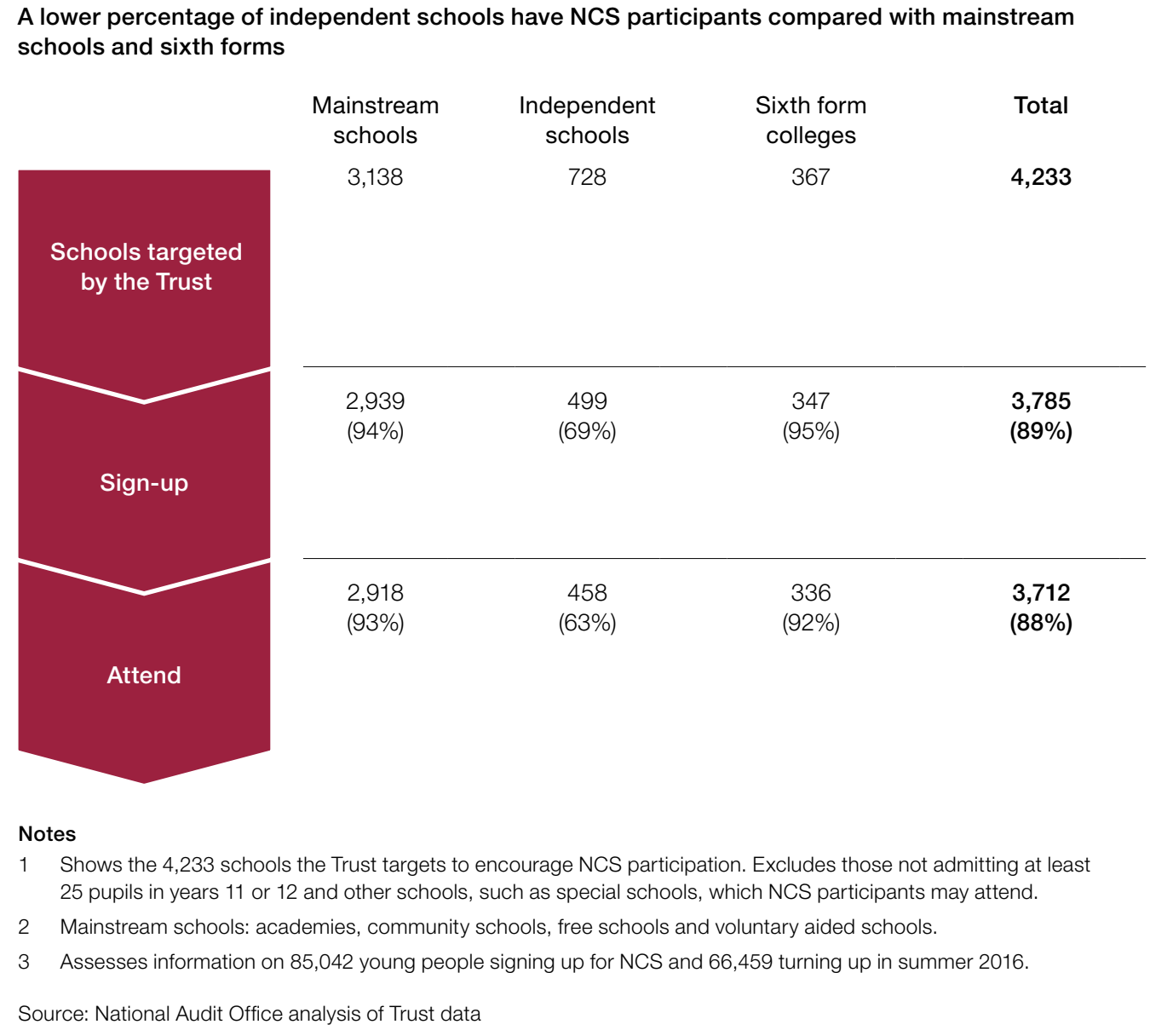

Annual participation targets

2.12 Annual stretch participation targets have not yet been met. The Trust missed its 2016-17 annual target of 107,000 by nearly 14,000 (13\%) (Figure 13 on page 35). The OCS sets the Trust performance targets covering quality, value for money, demand and sustainability. In 2015-16, the Trust met 13 of its 22 performance targets (Appendix Four). 


\section{Figure 12}

NCS participants at each stage, spring 2015 to autumn 2016

Around three-quarters of young people expressing an interest in 2016 did not complete the programme

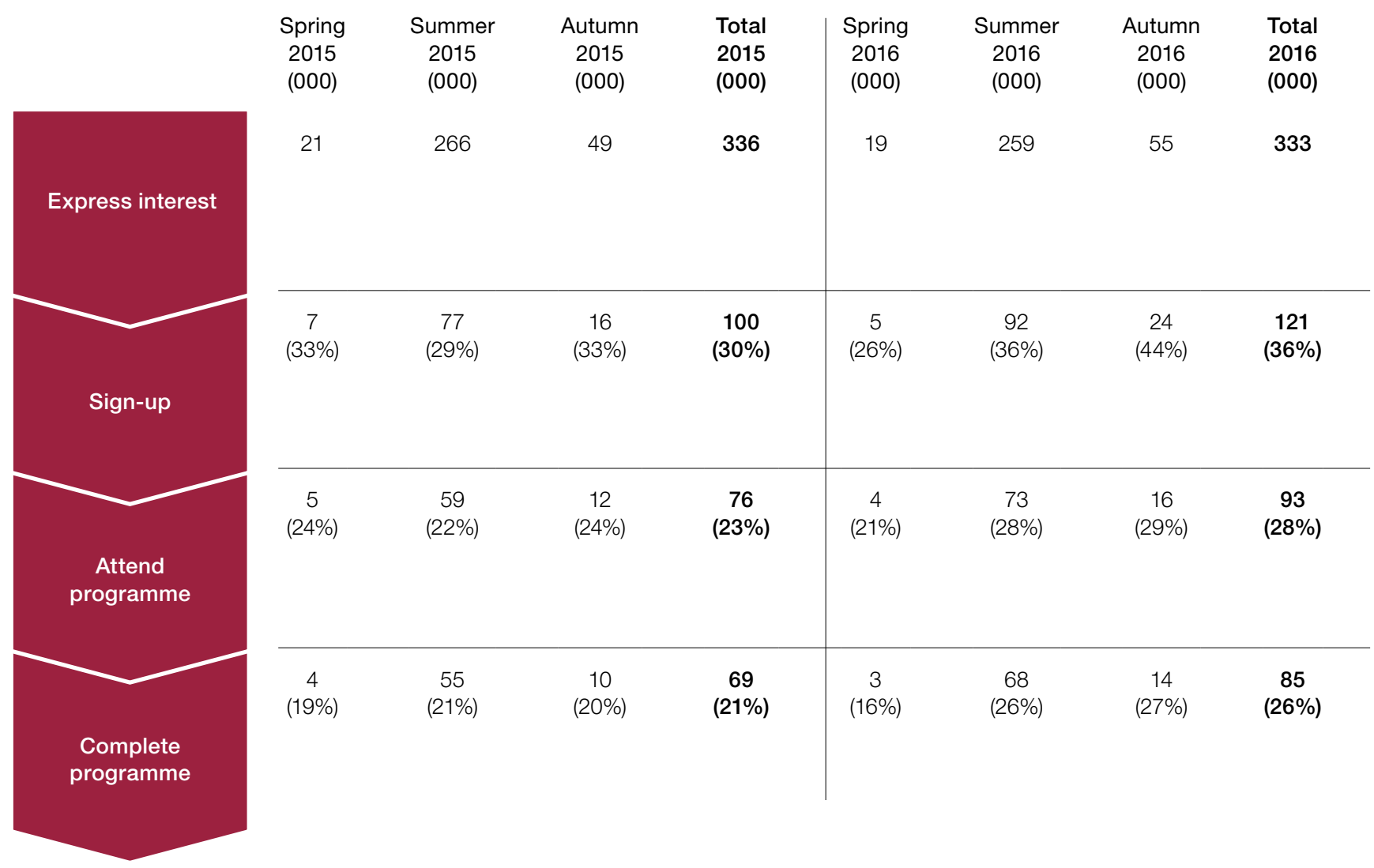

\section{Notes}

1 Percentages show the proportion of those expressing an interest in NCS who subsequently sign up, attend or complete the programme. The Trust expects fewer participants for the spring and autumn programmes, as compared with summer.

2 Comparisons cannot be made between 2015 and 2016 expressions of interest given changes to the operational process and the definition of an expression of interest.

2.13 The OCS has set participation targets without considering performance in previous years or what could be achieved. The 2015-16 grant agreement set a target for 110,000 participants, with a minimum performance threshold of 90,000 young people. ${ }^{10}$ This exceeded the 85,000 places the Trust had contracted to provide by $29 \% .^{11}$ The $2015-16$ target required participant numbers to increase $90 \%$ from 2014, significantly more than the actual annual growth of 31\% between 2014 and 2015. For 2016-17, the OCS set the annual grant target equal to the contracted number of places, rather than balancing this against an understanding against what they both can, and aspire, to achieve.

10 If the Trust does not meet the minimum performance threshold this is classed as performance failure under the terms of the grant. The OCS can then take further action.

11 Reflects adjustments to the contracted number of places agreed throughout the year which reduced the number of contracted placed from 87,708 . 

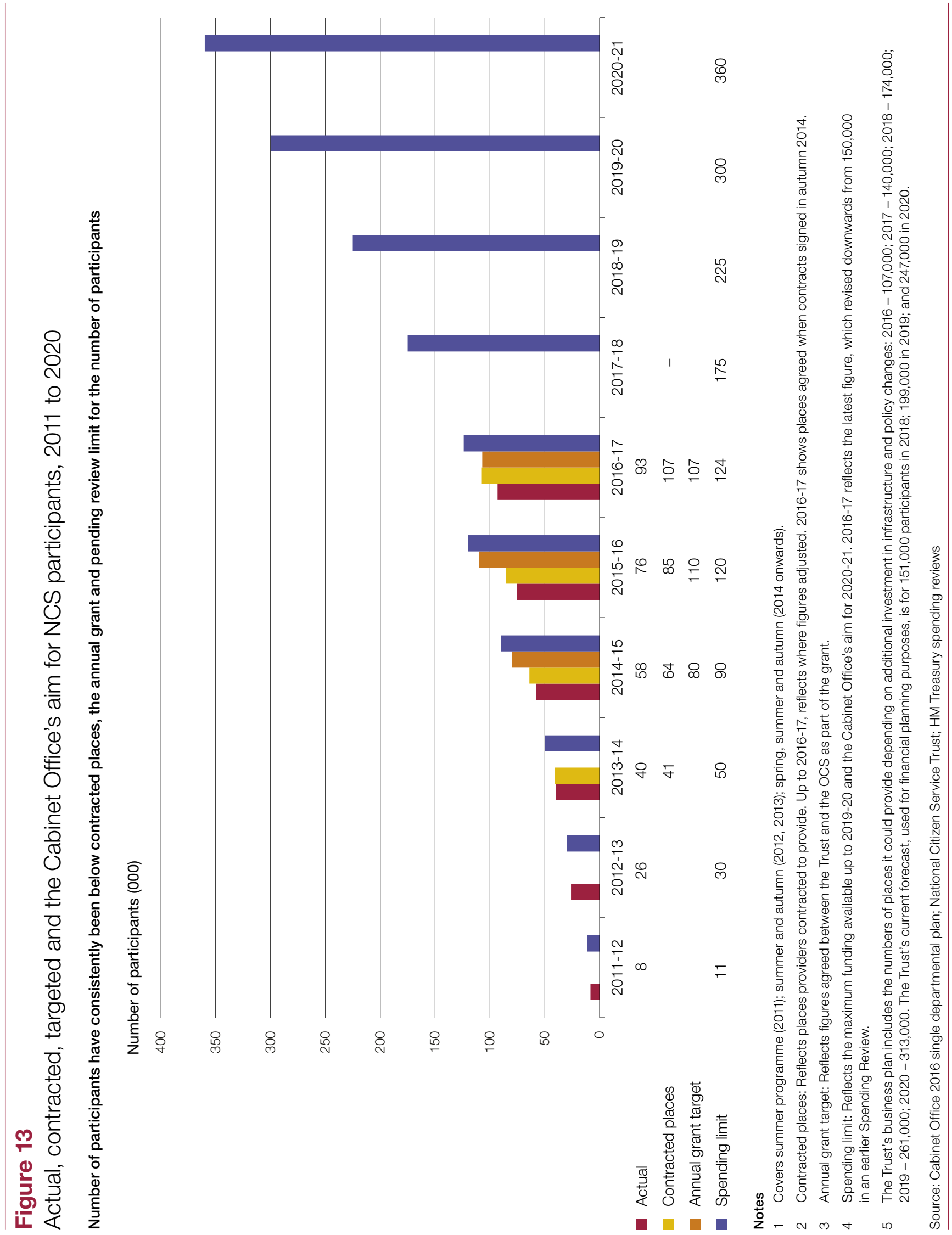


\section{Impact of the aims for growth}

2.14 Ambitious aims and targets have encouraged growth in the number of NCS participants but have also created tensions. The Trust and most providers told us that the focus on targets, and not meeting these targets, had a negative impact on staff morale, market interest and public perceptions of the programme.

2.15 The Trust has also focused significant efforts on growth targets compared to broader programme performance. We found that the Trust's board spent high proportions of its time discussing participation numbers, growing demand and agreeing grant terms with the OCS (Figure 14). A continued emphasis on participation risks impacting performance in other areas, such as quality.

2.16 Ambitious aims and targets have also impacted costs. They have contributed to:

\section{- High investment/high return media campaigns}

Given the need for rapid growth, the Trust invested in raising awareness through more costly media campaigns such as TV advertising, spending £2.7 million in 2016. It told us that without such high targets it could have shifted resources towards other levers to grow NCS, which may have been cheaper and more sustainable.

\section{- Paying providers for places that cannot be filled}

In 2016, the Trust paid an estimated £10 million for places not filled. In 2016, for the first time, it commissioned auditors to audit the performance of five providers not filling their commissioned number of places to recover some of the amounts paid. This audit is currently ongoing.

\section{- Running programmes in spring and autumn}

Successive evaluations show that young people who participate in the shorter autumn and spring programmes are less positive about the programme. Evaluations show central estimates from an estimated return on investment of £1.33 for every £1 spent for the autumn 2014 programme, compared with $£ 2.08$ for the summer. The Trust believes the autumn programme requires a disproportionate effort and is thinking about the balance of participants across programmes. In January 2016, providers could choose to provide fewer places during spring and increase places in summer. The Trust decommissioned 3,000 places for spring 2016 across all providers. 


\section{Figure 14}

Focus of NCS Trust board discussions, January 2015 to March 2016

The NCS Trust board has spent most time discussing funding, participation and growth

\begin{tabular}{|c|c|c|}
\hline Theme & Examples of discussion areas & Proportion of time \\
\hline $\begin{array}{l}\text { Participation numbers } \\
\text { and growth }\end{array}$ & $\begin{array}{l}\text { Likelihood of achieving annual target, including } \\
\text { number of places filled }\end{array}$ & High \\
\hline Funding & Whether to agree new grant terms and structure & High \\
\hline \multirow[t]{3}{*}{ Marketing } & Delays in OCS budget approval & Medium \\
\hline & $\begin{array}{l}\text { Impact of marketing campaign on increasing the } \\
\text { number of young people signing up }\end{array}$ & \\
\hline & Additional funding requests & \\
\hline Provider contracts & Management of underperforming providers & Medium \\
\hline \multirow[t]{2}{*}{$\begin{array}{l}2015 \text { Spending Review } \\
\text { and business plan }\end{array}$} & $\begin{array}{l}\text { NCS support from Department for Education/ } \\
\text { schools for } 2020 \text { target }\end{array}$ & Medium \\
\hline & $\begin{array}{l}\text { Options and need for NCS policy support to } \\
\text { achieve a stretch target }\end{array}$ & \\
\hline Costs & Meeting unit costs target & Low \\
\hline \multicolumn{3}{|c|}{ Note } \\
\hline \multicolumn{3}{|c|}{$\begin{array}{l}1 \text { Proportion of time based on the number of board minute paragraphs concerning each theme as a proxy for } \\
\text { time. Assumed high proportion of time is greater than } 15 \% \text { and a low proportion is less than } 5 \% \text { relative to } \\
\text { other themes discussed. }\end{array}$} \\
\hline
\end{tabular}




\section{Part Three}

\section{Setting up National Citizen Service to meet its aims}

3.1 To build a 'national institution' and quickly increase participation in National Citizen Service (NCS) the Office for Civil Society (OCS) and the NCS Trust (the Trust) need to develop NCS into a mature, sustainable programme. This part considers how well the OCS and the Trust have fulfilled these roles and, in particular, put in place effective commercial, cost and governance arrangements.

\section{Establishing a mature programme}

3.2 The OCS set up the Trust as an independent community interest company to provide NCS from 2014. It has regular discussions with the Trust to monitor the grant agreement. The Trust provides NCS through contracts with providers across 19 regions. ${ }^{12}$ It has oversight of provider performance and effectively followed up poor performance. However, the OCS and Trust only began to take the step-change needed to improve their understanding and establish what was needed to grow NCS to the levels aspired from 2016. This includes:

\section{- Enhancing staff capability}

The Trust has grown rapidly from 29 employees in 2013 to 101 in November 2016.13 This included recruiting to strategic positions in summer 2016, such as chief people officer, and commercial expertise to develop the specification for contracting new providers from autumn 2018.

\section{- Data analysis}

Before 2015, the Trust relied on providers' systems for data on participants and provider activities. It has now improved its data, with all providers using a single, data system, and developed its ability to analyse data. Building on this, the Trust is now trying to better understand what influences regional performance and is undertaking a review to identify and share good practice across providers. 


\section{Learning from experience}

3.3 As a new programme, NCS cannot fairly be expected to achieve 'success' from the outset. Successful innovation depends on clear drivers, strong incentives, an absence of barriers to implementation, and ways of learning and of replicating success. ${ }^{14}$ Given that NCS is now five years in, we would expect the OCS and Trust to be continually testing, evaluating and improving the programme as a whole and operational processes.

3.4 The OCS and Trust have gone some way to learn from experience by, for example, the Trust agreeing longer contracts with providers to allow them to plan ahead. However, although programme outcomes are evaluated, they have not taken a systematic approach to testing, evaluating and learning about different approaches to delivering the programme. This has been hindered by gaps in data and knowledge before 2016 and not building time to learn into the process. Having a sequence of programmes in spring, summer and autumn allows little time to consider what works and think strategically. The Trust and the OCS spent around six months developing plans to increase participation to 360,000 young people in $2020-21$, alongside continuing to grow NCS.

3.5 For the first time in 2016-17, the OCS split out payments to fund the Trust's expansion of its capacity and capability which had previously been part of total Trust funding. The Trust also ran its first pathfinder in autumn 2016 to identify innovative ways to sign up young people outside of schools (paragraph 3.13). It recognises that when planning pilots it could think through its approach more rigorously.

\section{Decision-making arrangements}

3.6 The annual grant cycle has not encouraged the Trust and OCS to plan ahead. The autumn 2015 Spending Review sets out the maximum funding available for NCS each year up to 2019-20. The OCS believes this, and the requirement for providers and the Trust to agree multi-year contracts, provides certainty over future funding. At a more detailed level, the OCS then agrees with the Trust an annual grant, which could differ from the Spending Review or contracts. The autumn 2015 Spending Review provided up to £217 million for 124,000 to participate in NCS whilst the 2016-17 annual grant provided the Trust £203 million to provide 107,000 places.

3.7 The annual grant cycle has contributed to decisions being made late in the operational cycle which limits available options, creates inefficiencies, makes planning more difficult and takes up management time at critical stages of the process. For example, the OCS and Trust agreed the 2016-17 grant, including the target participation numbers and available funding, in March 2016. This covered the summer 2016 programme, which the Trust and providers had started to plan at least six months earlier and the Trust had been paying providers for since October 2015 (Figure 15 overleaf). Before then, the spending review had confirmed funding would be available whilst contracts, agreed with providers in 2014, included a number of commissioned NCS places. 


\section{Figure 15}

\section{Planning cycle for the summer 2016 NCS programme}

\section{The OCS and Trust introduced requirements and changes late in the operational cycle}

\section{Planning}

Eg secure accommodation and outbound activities; plan staff recruitment and marketing

\section{Young people sign up}

Eg National and regional marketing, liaison with schools, staff recruitment
Young people attend programme followed by 'graduation'

\section{From Sep \\ Q3 2015-16 Jan to Mar \\ Q4 2015-16 Jan to Mar \\ Q1 2016-17 Apr to Jun \\ Oct \\ Providers receive first monthly payment from Trust

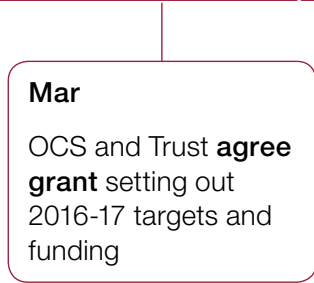

Q2 2016-17 Jul to Aug

Notes

1 Certain investment decisions require greater planning periods, such as office locations.

2 Providers receive 15\% of total programme cost in October and November with $10 \%$ each subsequent month.

3 Alongside dedicated marketing funding received in April 2016, the Trust can use funding already received for regular marketing activities.

Contract changes introduce a higher threshold for providers to receive some payments and new performance standards.

3.8 The requirement for separate marketing funding requests to be approved after the grant has been signed has influenced the options that can be considered and potential impact of marketing activity. The 2016-17 grant agreement includes £19.3 million of funding contingent on the OCS approving a business case to support spend. This additional control gives the OCS greater assurance over spending but may restrict the Trust's ability to be responsive and flexible. In April 2016, the Trust applied for £2.5 million to market the summer programme. The OCS approved funding three weeks later. 


\section{Current commercial arrangements}

3.9 The Trust agreed 19 regional contracts with ten voluntary and private sector providers to provide NCS up to and including summer $2018 . .^{15}$ This replaced more local contracts, agreed in 2012, that aimed to develop NCS's community presence and provide better interaction with young people. Regional contracts prevented coordination problems and confusion for young people and schools.

3.10 Providers received $83 \%$ of total NCS spending in 2016-17 to market NCS locally, sign up young people, recruit and train their staff and run the programme. They receive payments based on a total contract cost, with $50 \%$ paid up front and the remainder contingent on meeting performance targets (Figure 16 overleaf). The total contract cost combines an agreed unit cost per participant and a contracted number of places.

3.11 Through a payment by results approach, the contracts aim to incentivise providers to increase the number of NCS participants. It encourages providers to agree a high number of commissioned places. The Trust pays providers up to $10 \%$ over this number of places and, from summer 2016, bonus payments where the number of young people completing NCS exceeds $80 \%$. However, in 2016 , five of the nine providers significantly missed their participation targets. Providers told us they needed to invest more time in encouraging higher numbers of young people through further school assemblies or more direct, regular contact. This created additional costs, which could outweigh the payments received.

3.12 The contract structure does not explicitly incentivise providers to meet all the NCS aims or grow NCS to the level aspired by OCS and the Trust. For example:

\section{- $\quad$ Meeting NCS aims}

Providers receive $5 \%$ of the total contract cost if they achieve a mix of participants proportional to the local authority population. This aligns with the aim of NCS to improve social cohesion but does not explicitly encourage providers to consider other aims, such as greater social responsibility and engagement, or to think more innovatively about what can be achieved. The Trust told us it encourages innovation through other means, such as the sharing of best practice.

- Encourage long-term growth

Providers get paid for providing up to $10 \%$ over the places commissioned by the Trust. The existing contracts, agreed in 2015, guarantee provision until summer 2018. As such, providers are not given the security needed to invest in processes and contracts to support growth beyond 2018. Current providers expressed concern at not being able to reach 360,000 participants in 2020 .

15 Four contracts began in November 2014 to provide NCS from spring 2015. The remaining 15 ran from April 2015 In summer 2015, the Trust terminated one contract, and now provides NCS in that region. 


\section{Figure 16}

\section{Commercial costing structure}

\section{Breakdown of provider payment structure}

\begin{tabular}{|c|c|c|c|}
\hline Payment type & $\begin{array}{l}\text { Percentage of total } \\
\text { contract cost } \\
(\%)\end{array}$ & Payment frequency & Purpose \\
\hline Core & 50 & $\begin{array}{l}\text { Monthly from nine to } \\
\text { six months before }\end{array}$ & $\begin{array}{l}\text { Covers up front costs such as } \\
\text { staffing and equipment }\end{array}$ \\
\hline Sign-ups & 20 & $\begin{array}{l}\text { Month after sign-up } \\
\text { registered }\end{array}$ & $\begin{array}{l}\text { Incentive to sign up } \\
\text { participants early }\end{array}$ \\
\hline Turn-ups & 22.5 & $\begin{array}{l}\text { Month after } \\
\text { turn-up registered }\end{array}$ & $\begin{array}{l}\text { Incentive to fill all contracted } \\
\text { places. Performance can } \\
\text { exceed target by maximum 10\% }\end{array}$ \\
\hline Social mix & 5 & $\begin{array}{l}\text { Month after end } \\
\text { of season }\end{array}$ & $\begin{array}{l}\text { Incentive to achieve a specified } \\
\text { social mix of young people } \\
\text { across ethnicity, free school } \\
\text { meal entitlement and special } \\
\text { educational needs }\end{array}$ \\
\hline Completion & 18 & $\begin{array}{l}\text { Month after end } \\
\text { of season }\end{array}$ & $\begin{array}{l}\text { Incentive to ensure } 80 \% \text { or more } \\
\text { of participants complete NCS }\end{array}$ \\
\hline Total & 115.5 & & \\
\hline Satisfaction & $\begin{array}{l}\text { Up to } £ 10 \text { bonus } \\
\text { per completion }\end{array}$ & $\begin{array}{l}\text { Month after end } \\
\text { of season }\end{array}$ & $\begin{array}{l}\text { Rewards quality - payment for } \\
\text { each young person with more } \\
\text { than } 75 \% \text { satisfaction score }\end{array}$ \\
\hline \multicolumn{4}{|l|}{ Notes } \\
\hline \multicolumn{2}{|l|}{$\begin{array}{l}1 \text { Providers ma } \\
\text { completion to }\end{array}$} & cost should they receive & pletion payments for exceeding their \\
\hline \multicolumn{4}{|c|}{$\begin{array}{l}2 \text { Reflects contract variation, effective January } 2016 \text {, which increased the percentage of costs to be paid for } \\
\text { completions and introduced } 80 \% \text { threshold; reduced the maximum threshold up to which payments could be } \\
\text { made from } 115 \% \text { to } 110 \% \text { and introduced performance standards. }\end{array}$} \\
\hline
\end{tabular}


3.13 The Trust has in place processes to monitor provider performance and respond to poor performance, but has made a number of recent commercial decisions which have a disproportionate impact on providers. Our wider commercial work emphasises that organisations need to sustain market interest throughout a contract and continually consider the impact of their decisions. ${ }^{16}$ The NCS process relies on some small, local or voluntary providers who often have limited financial resources and lower ability to absorb risk or respond to changes quickly. The Trust has not always thought through the commercial consequences of decisions, for example in:

\section{- changing contracts at short notice}

In December 2015, the Trust informed providers of a significant contract variation. This introduced new minimum standards for assessing performance and altered payment terms. The Trust and providers agreed this change - effective from January 2016 - in June 2016, only one month before programmes started. Providers told us they were given little warning of the proposed changes, although they felt the Trust responded well when discussing their concerns; and

- altering the commercial balance of risk through new schemes in competition to existing arrangements

In July 2016, the Trust requested proposals for a series of pathfinders in autumn 2016 to identify innovative approaches to signing up young people outside of mainstream schools. On 5 September 2016, one month before the autumn programme was due to start, it announced that 18 organisations had been offered contracts to provide more than 2,200 NCS places. At this point, existing providers had received $80 \%$ of their core funding and had been signing up participants. They told us one impact of the pathfinder was a lack of transparency about the impact of pathfinders on existing contracts, which required the Trust to give them a full season's notice of any intention to run pilots.

3.14 The Trust is currently reviewing its commercial arrangements before existing contracts expire in autumn 2018. This presents the Trust with an opportunity but it only has 18 months to complete its work to engage the market, develop a commercial strategy, contract providers and establish transition arrangements. Since autumn 2016 it began market engagement and building expertise but is still considering options for the future commercial model. This will need to reflect that one provider supplies $43 \%$ of NCS places and some providers put their own brand on NCS activities. Although this could improve local engagement with parents and young people and incentivise providers to provide a quality NCS, it may create risks transitioning from the supply chain. 


\section{Costing arrangements}

3.15 To date consecutive spending reviews have allocated funding for all those wishing to participate in NCS. By the end of 2015-16, the government had invested £443 million and committed to provide a further £1.26 billion to 2019-20.

3.16 The OCS has not prioritised understanding how much NCS should cost and controlling costs. It has not developed a full cost model to understand what it should be paying the Trust and told us it requests funding from HM Treasury based on contractor costs. As part of the annual grant agreement, it requires the Trust to improve value for money and reduce costs. In 2016-17, the OCS started to monitor the full cost per participant. Before then, it monitored a provider-cost based unit cost and total programme management and administrative spend.

3.17 The Trust has spent little time understanding costs and where savings could be made. The Trust has four strategic objectives: growth; quality; cost and sustainability. Its business plan includes a number of cost control initiatives at the early stages of implementation. This includes establishing a central procurement function to drive down costs. Our analysis shows the Trust's board has not focused on costs (Figure 14 on page 37), although it told us that in 2017 it saw reducing costs as one of four main priorities alongside demand, quality and stakeholder engagement. It uses a cost model to understand and plan payments to providers. The model does not estimate how much NCS should be costing, for example when contracts are recommissioned. The Trust is currently auditing provider costs.

3.18 Based on a full unit cost, NCS risks being financially unsustainable in the future. Our analysis shows that in 2016, the estimated full unit cost exceeded the expected unit cost by 19\% (Figure 17). On this basis, it will cost government $£ 560$ million to provide 300,000 places in $2019-20,32 \%$ more than the $£ 424$ million funding currently allocated. The unit cost will need to fall 29\% from £1,863 in 2016 to £1,314 in 2019 to provide these places within the available spending envelope. Over 2016-17 the Trust's target, as agreed by the OCS and Trust in the grant, is to reduce unit cost to $£ 1,794$. It is unclear how this unit cost is calculated. The OCS and the Trust forecast unit costs will decrease over time as participation numbers increase and they reconsider how NCS will be delivered.

3.19 The Trust has limited control over actual NCS costs. It pays providers a unit cost per participant, reducing each year, agreed at the start of the contract (paragraph 3.11). For such contracts to achieve best value the initial price needs to be 'right' or continually revisited throughout the contract. The Trust's approach did not allow it to:

\section{- Evaluate costs}

Providers were selected based primarily on their proposal and experience rather than cost. Commercial considerations, which included pricing as well as transparency and innovation, were given a $30 \%$ weighting when evaluating the bids. The Trust told us this was to focus on quality and attract bids from smaller organisations across the social sector. 
- Understand costs

During the bidding process, the Trust did not benchmark bids against its own understanding of what it should pay for NCS. Unit costs per participant varied by $23 \%$. The Trust could not confirm how much costs differed from what they wanted to pay.

\section{- $\quad$ Monitor costs}

The Trust agreed unit costs at the start of the contract in 2015, but it has not revisited them. In agreeing a four-year contract with no way of challenging and reducing costs throughout, the Trust risks paying for more than it should, with providers choosing the cheapest option to reduce costs.

3.20 The 2016-17 grant agreement also sets out the Trust's responsibility for raising $£ 10$ million in corporate contributions (including £1 million in cash funding). The Trust does not forecast to reach this figure and has secured $£ 7$ million in corporate sponsorships and discounts in 2016-17.

\section{Figure 17}

Actual and expected estimated cost per NCS participant, 2014 to 2019

NCS is costing more than planned per participant

\begin{tabular}{|c|c|c|c|c|c|c|}
\hline & 2014 & 2015 & 2016 & 2017 & 2018 & 2019 \\
\hline \multicolumn{7}{|l|}{ Provision } \\
\hline Funding (£m) & 130 & 147 & 194 & 239 & 319 & 394 \\
\hline $\begin{array}{l}\text { Maximum participant } \\
\text { numbers }(000)\end{array}$ & 90 & 120 & 124 & 175 & 225 & 300 \\
\hline Unit cost $(£)$ & 1,444 & 1,222 & 1,562 & 1,368 & 1,418 & 1,314 \\
\hline Actual/Forecast & \multicolumn{3}{|c|}{ Actual } & \multicolumn{3}{|c|}{ Forecast } \\
\hline Spend (£m) & 105 & 141 & 175 & 249 & 319 & 394 \\
\hline Participant numbers (000) & 58 & 76 & 93 & 110 & 151 & 199 \\
\hline Unit cost $(£)$ & 1,826 & 1,825 & 1,863 & 1,856 & 1,698 & 1,536 \\
\hline \multicolumn{7}{|l|}{ Notes } \\
\hline \multicolumn{7}{|c|}{$\begin{array}{l}1 \text { To determine the actual and available participant cost per calendar year, financial year spend has been apportioned } \\
\text { across calendar years based on the timing of the Trust's payments to providers. This has been used as a proxy for } \\
\text { apportioning all Trust and OCS spending. }\end{array}$} \\
\hline \multicolumn{7}{|c|}{$\begin{array}{l}2 \text { Provision: Reflects HM Treasury Spending Review } 2013 \text { and 2015. In 2016-17 actual spend includes an estimated } \\
\text { £18 million funding to cover the Trust's expansion of capacity and capability which not included in previous years. }\end{array}$} \\
\hline \multicolumn{7}{|c|}{$\begin{array}{l}3 \text { Actual/Forecast: Includes all amounts spent by the Trust and OCS (Figure 8). NCS costs do not include the non-cash } \\
\text { benefits received as corporate contributions. Forecast participation numbers represent the Trust's current forecast } \\
\text { used for financial planning purposes. }\end{array}$} \\
\hline
\end{tabular}




\section{Appendix One}

\section{Our audit approach}

1 This study assesses how well the Cabinet Office, in particular the Office for Civil Society (OCS), has implemented National Citizen Service (NCS) up to autumn 2016. We examined:

- $\quad$ early programme performance;

- the OCS's approach to setting out its aims and targets; and

- $\quad$ how well the OCS and the NCS Trust's (the Trust's) processes and systems have been set up to support NCS and the planned growth.

2 Our audit approach is summarised in Figure 18. Our evidence base is described in Appendix Two. 


\section{Figure 18 \\ Our audit approach}

\section{The objective of government}

\section{How this will} be achieved

\section{Our study}

Our evaluative criteria

\section{Our evidence}

(see Appendix Two for details)

\section{Our conclusions}

To promote a more:

- cohesive society by mixing young people with contemporaries from different backgrounds;

- responsible society by supporting their transition into adulthood and equip them with essential skills; and

- engaged society by enabling young people to get involved in their local community.

National Citizen Service (NCS) is a voluntary programme for 16- and 17-year-olds designed to meet government's objectives. The aim is to increase the number of NCS participants so it becomes 'universal' for young people.

The study examines whether the OCS's implementation of NCS has been value for money and the future risks to the programme.

\begin{tabular}{|c|c|c|}
\hline$\downarrow$ & $\nabla$ & $\downarrow$ \\
\hline $\begin{array}{l}\text { Early performance against } \\
\text { expected performance and } \\
\text { national/local characteristics. }\end{array}$ & $\begin{array}{l}\text { Approach to setting out aims and } \\
\text { targets, including understanding } \\
\text { performance, evidence base } \\
\text { for targets and agreement with } \\
\text { third parties. }\end{array}$ & $\begin{array}{l}\text { How well processes and systems } \\
\text { are set up to support growth } \\
\text { including funding and cost } \\
\text { control, and a clear operating } \\
\text { model reflecting operational } \\
\text { and commercial constraints. }\end{array}$ \\
\hline$\nabla$ & $\nabla$ & $\downarrow$ \\
\hline $\begin{array}{l}\text { - interviews with the OCS, } \\
\text { Trust and other stakeholders; } \\
\text { - } \quad \text { programme visits; } \\
\text { - data analysis; and } \\
\text { - review of announcements, } \\
\text { documents and } \\
\text { progress reports. }\end{array}$ & $\begin{array}{l}\text { - interviews with the OCS } \\
\text { and Trust officials; } \\
\text { - data analysis; and } \\
\text { - review of documents, } \\
\text { and other material. }\end{array}$ & $\begin{array}{l}\text { - interviews with the OCS, } \\
\text { Trust officials and providers; } \\
\text { - data analysis; and } \\
\text { - review of documents, } \\
\text { and other material. }\end{array}$ \\
\hline
\end{tabular}

It is still early days, but NCS has shown it can attract large numbers of participants and participation has a positive short-term effect on young people. These are no small achievements. However, it remains unclear whether these effects are enduring, whether NCS can grow to become 'a rite of passage' available to all 16- to 17-year-olds or whether NCS will realise its longer-term aims of contributing to social cohesion, responsibility and engagement.

NCS is now at a critical stage. Having shown the concept of a national citizen service has something to offer young people, to demonstrate value for money the OCS and Trust now need to show they can grow NCS as intended and run it at more affordable cost to the taxpayer. As currently constituted, it is not clear how the programme will do this. Weaknesses in governance and cost control need to be addressed. Notwithstanding the limited time available to adjust the next round of contracts, the OCS and Trust need to think carefully about their plans to take NCS to scale. 


\section{Appendix Two}

\section{Our evidence base}

1 We reached our independent conclusions on how well the Cabinet Office, in particular the Office for Civil Society (OCS), has implemented National Citizen Service (NCS) up to autumn 2016 following our analysis of evidence collected between June and November 2016. Our audit approach is outlined in Appendix One.

\section{We examined the OCS's development of NCS and how well it is achieving its aims:}

- We conducted semi-structured interviews with officials from the OCS and NCS Trust (the Trust) to understand NCS's aims and objectives and how the Trust has developed.

- We conducted semi-structured interviews with organisations representing young people in summer 2016, to understand the wider environment in which NCS operates and gather perceptions on how well NCS is progressing, as follows:

- UK Youth.

- Ambition UK.

- British Youth Council.

- We visited components of an NCS programme to better understand how the programme is provided and participants experiences. This included a social project (summer 2016), a graduation ceremony (summer 2016) and an outdoor residential (autumn 2016).

- We analysed Trust data:

- on participants in 2015 and 2016 to establish NCS participants to date;

- on participant characteristics to understand who undertakes NCS and how this compares to characteristics of those across local authorities. We compared with other data such as census data and Department for Education data on free school meals;

- NCS participant satisfaction data and feedback on social media to identify participants' experiences and whether NCS is achieving its short-term aims; and

- cost data and projected cost and income data to 2019-20 to establish the cost of delivering the programme to date and to the end of the current Spending Review period. 
- We reviewed published policy announcements, government press releases and documents.

- We reviewed NCS evaluation reports to understand participant numbers and NCS's impact on participants.

- We reviewed online literature to understand the structure of similar schemes abroad.

3 We assessed whether the OCS has an effective approach to setting its aims and targets, and for measuring the impact of these:

- We conducted semi-structured interviews with officials from the OCS and Trust to understand how longer-term aims are set and are planned to be met.

- We analysed data on the expected and actual growth in NCS participants to understand the scale of the OCS's ambition. This comprised data taken from NCS evaluation reports and the Trust's projections.

- We analysed the Trust's performance data to understand those young people expressing an interest in NCS through to those completing the programme.

- We reviewed the OCS and Trust documents including the Trust's business plan to 2020 and the OCS's NCS business cases.

4 We considered whether the OCS and NCS Trust have effective processes and systems in place to support NCS now and to 2020 .

- We conducted semi-structured interviews with:

a officials from the OCS and Trust to understand the grant arrangements in place between the OCS and Trust and the contract arrangements between the Trust and providers; and

b all regional providers contracted to provide NCS across England to understand NCS's commercial arrangements. This included:

- $\quad$ Advanced Personnel Management group (UK) Ltd;

- CXK Ltd;

- $\quad$ EBP, Lincolnshire and Rutland;

- Ingeus UK Ltd;

- Inspira Cumbria Ltd;

- $\quad$ Reed in Partnership Ltd;

- The Challenge Network;

- EFL Trust; and

- vinspired. 
- We analysed the Cabinet Office's single departmental plan to understand their aims for NCS participants in the period to 2020 and compared these to actual places, contracted places and grant targets.

- We analysed the Trust's board minutes to understand topics of board discussions and proportion of time spend on each of these to understand the focus of the board.

- We analysed the Cabinet Office's annual report and accounts and the Trust's forward plans to identify unit costs over time.

- We reviewed the OCS and Trust documents, including the 2016-17 grant agreement and current regional provider contracts, to understand the arrangements in place. 


\section{Appendix Three}

\section{Comparison of selected youth programmes}

\section{Figure 19}

Comparison of selected youth programmes in the United Kingdom and other countries

\begin{tabular}{|c|c|c|c|}
\hline & National Citizen Service & Service Civique & $\begin{array}{l}\text { Americorps - National } \\
\text { Civilian Community }\end{array}$ \\
\hline Country & $\begin{array}{l}\text { England and } \\
\text { Northern Ireland }\end{array}$ & France & USA \\
\hline Date started & 2011 & 2010 & 1993 \\
\hline Participant age (years) & 16 to 17 & 16 to 24 & 18 to 24 \\
\hline Average annual participants & 93,000 & 53,000 & $\mathrm{n} / \mathrm{a}$ \\
\hline Aim & $\begin{array}{l}\text { Support local community } \\
\text { and transition into adulthood } \\
\text { by mixing those from } \\
\text { different backgrounds }\end{array}$ & $\begin{array}{l}\text { Reinforce social cohesion } \\
\text { and social mixing }\end{array}$ & $\begin{array}{l}\text { Strengthen communities } \\
\text { and develop leaders }\end{array}$ \\
\hline Key aspects & $\begin{array}{l}\text { Two- to four-week } \\
\text { programme combining } \\
\text { outbound activities, } \\
\text { skills development and } \\
\text { community projects costing } \\
\text { families £50 per participant }\end{array}$ & $\begin{array}{l}\text { Paid, full-time role for six } \\
\text { to } 12 \text { months to complete } \\
\text { 'voluntary mission' }\end{array}$ & $\begin{array}{l}\text { Teams complete projects } \\
\text { responding to local } \\
\text { communities' needs } \\
\text { (four to eight weeks) }\end{array}$ \\
\hline
\end{tabular}




\section{Appendix Four}

\section{National Citizen Service Trust performance against 2015-16 grant agreement}

\section{Figure 20}

National Citizen Service (NCS) Trust performance against 2015-16 grant agreement

In 2015-16, the Trust met 13 of its 22 performance targets

\begin{tabular}{|c|c|c|c|}
\hline & Target & Actual & Met? \\
\hline \multicolumn{4}{|l|}{$\begin{array}{l}\text { Objective } 1 \text { : Increase demand to fill places and improve retention } \\
\text { of participants }\end{array}$} \\
\hline Total number of filled places & 90,000 & 75,605 & No \\
\hline Number of filled places by completion of spring programme & 5,400 & 4,671 & No \\
\hline Number of filled places by completion of summer programme & 72,900 & 64,142 & No \\
\hline Number of filled places by completion of autumn programme & 90,000 & 75,605 & No \\
\hline Participant completion rate & $90 \%$ & $91 \%$ & Yes \\
\hline Willingness to take part in NCS in future & $52 \%$ & $67 \%$ & Yes \\
\hline Awareness of NCS among 16- to 17-year-olds & $60 \%$ & $46 \%$ & No \\
\hline Brand relevance/affinity: 'a brand for someone like me' (\%) & $56 \%$ & $56 \%$ & Yes \\
\hline Advocacy: prepared to refer a friend to NCS (\%) & $44 \%$ & $39 \%$ & No \\
\hline \multicolumn{4}{|l|}{ Objective 2: Ensure delivery of high-quality NCS places } \\
\hline $\begin{array}{l}\text { Proportion of graduates that would definitely recommend } \\
\text { NCS to a friend }\end{array}$ & $90 \%$ & $84 \%$ & No \\
\hline $\begin{array}{l}\text { Number of local authorities who achieve NCS requirement } \\
\text { of social mix (\%) ie meet the following indicators for social } \\
\text { mix - ethnicity }\end{array}$ & $89 \%$ & $88 \%$ & No \\
\hline $\begin{array}{l}\text { Number of local authorities who achieve NCS requirement of } \\
\text { social mix (\%) ie meet the following indicators for social mix } \\
\text { - free school meals }\end{array}$ & $90 \%$ & $91 \%$ & Yes \\
\hline $\begin{array}{l}\text { Number of local authorities who achieve NCS requirement of } \\
\text { social mix (\%) ie meet the following indicators for social mix } \\
\text { - special educational needs }\end{array}$ & $78 \%$ & $90 \%$ & Yes \\
\hline
\end{tabular}


Figure $\mathbf{2 0}$ continued

National Citizen Service (NCS) Trust performance against 2015-16 grant agreement

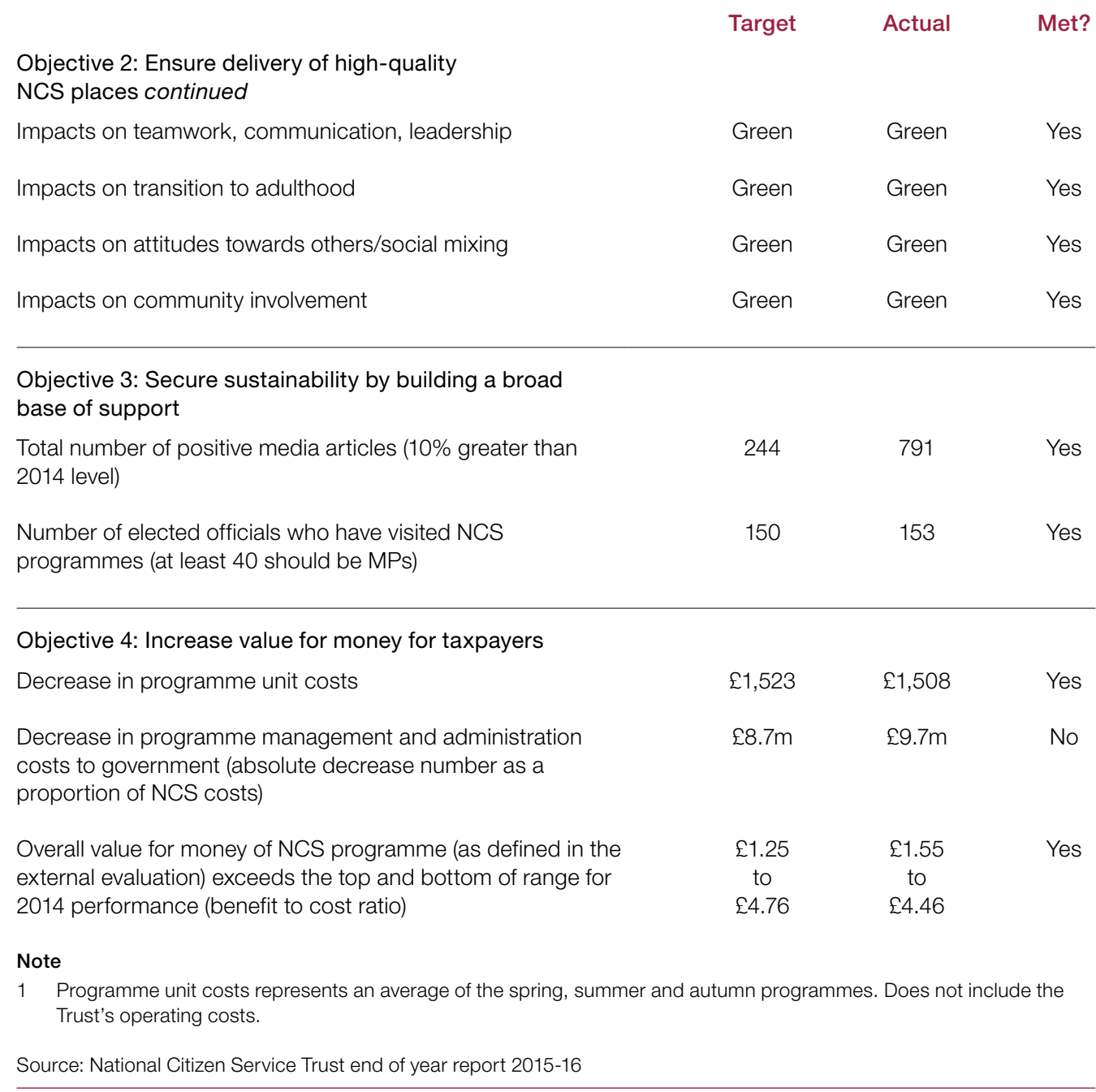


This report has been printed on Evolution Digital Satin and contains material sourced from responsibly managed and sustainable forests certified in accordance with the FSC (Forest Stewardship Council).

The wood pulp is totally recyclable and acid-free. Our printers also have full ISO 14001 environmental accreditation, which ensures that they have effective procedures in place to manage waste and practices that may affect the environment. 
$£ 10.00$

ISBN 978-1-78604-096-1

National Audit Office

Design and Production by NAO External Relations DP Ref: 11402-001 